علاقة نمطي الإنفوجرافيك بمستوى الوعي المعلوماتي لاى طلاب الجامعة في ضوء السعة العقلية

د.محمد ضاحي محمد توني (1)

ملخص البحث

هدف البحث الحسالي إلى الكثـف عـن علاقـة نمطي الإنفوجرافيـك

بمستوى الوعي المعلوماتي ، ولتحقيق هدف البحث استُخدم المنهج شبه التجريبي ، تم ضبط أداتا القياس المتمثلتين في إختبار الوعي المعلوماتي ومقياس السعة العقلية ، واعداد معالجتان تجريبيتان الأولى تمثلت في توظيف الإنفوجرافيك

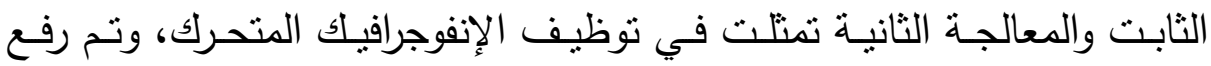
الملفات على بيئة إلكترونية ، وتكونت عينة البحث الأساسية من ، 1 ا طالباً مقسـمين إلى 1 مجموعـات وفـق مسـنتوى السـعة العقليـة (مرتفـع ، متوسـط ، منخفض) ونمط الإنفوجرافيك (ثابت ، متحرك) ، وأثنارت النتائج إلى التأثنير

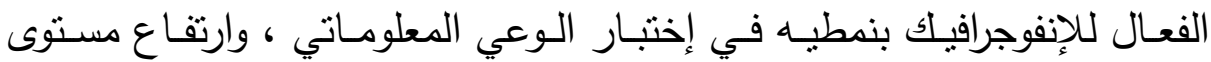
الطـلاب الذين اسـتخدموا الإنفوجرافيلك المتحـرك عن نظرائهم الذين استخدموا النمط الثابت ، كما أثنارت النتائج إلى تفوق الطلاب ذوي السعة العقلية المرتفعة عن نظرائهم منتوسطي ومنخفضي السعة العقلية في إختبار الوعي المعلوماتي ، بينما لم توجد فروق بين منتسطي ومنخفضـي السعة العقلية، يوصسي البحث بأهمية التوسع في استخدام الإنفوجرافيك وبمراعاة الاختلاف بين مستويات السعة لئ العقليـة لـدى المتعلمـين وبضـرورة الاهتمـام بتنميـة الـوعي المعلومـاتي لجميـع

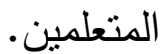

\title{
Abstract
}

The aim of the current research was to identify the relationship between two types of infographic and 
information awareness . To achieve the goal of the research, the semi-experimental method was used. measurement tools were information awareness test and mental capacity scale. Two experimental treatments were produced fixed infographic and animated infographic that were uploaded to an electronic environment. Basic research sample consisted of 180 students divided into 6 groups according to level of mental capacity (high, medium, low) and types of infographic (fixed, animated .(

Results showed the big effect of both kinds of infographic in information awareness test specialy animated infographic groups Results also indicated that students with higher mental capacity than their middle and low mental counterparts in information-awareness test, while there were no differences between medium and low-students, Study recommends the importance of expanding the use of infographic and taking into account differences between levels of mental capacity of learners and the need to pay attention to the development of information awareness of all learners.

مقدمة:

تتبع أهمية التعليم بشكل عام في تحسين وتطوير معارف ومهارات الفرد

ليقوم باستغلالها في مواقف حياته المختلفة ، ومن ناحية أخرى فإن التكنولوجيا بأثكالها المختلفة تستطيع أن تحديث تغييرا ملحوظا وجذريا في مستوى المتعلم وفرصا أكبر في تلقي المعلومات.

فرض النطور السريع والمؤثر في تكنولوجيا المعلومات ضرورة تحديث

أساليب وطرق التعلم وأيضا تطوير مداخل جديدة للتعليم تفيد كلا من المعلم والمتعلم ، ولذلك أصبح لزاما على التربوبين إعادة النظر في الأساليب والتقنيات المستخدمة في الفصول الدراسية. (Ozdamlı et al, 2016 ( 
نتيجة لهذا النطور زاد بشكل كبير عدد المقررات الدراسية التي تدمج أثنكال عرض محتوى غير نقليدية منل الرسومات التعليمية الإلكترونية بأثكالها الحديثة ، فهي تقوم إعادة تمثيل للنصوص التعليمية بطريقة تتفاعل فيها الأفكار

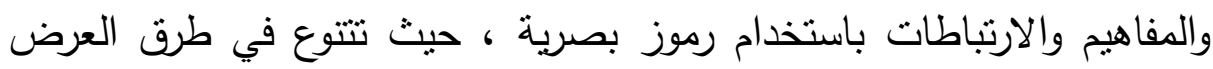
بطريقة تجعلها تمثل أي معلومات معقدة بأثكال سهلة الفهم والإدراكت.

(Rezaei \& Sayadian , 2015)

إن استخدام الصور والمثيرات البصرية مثل الإنفوجرافيك بسهل استدعاء

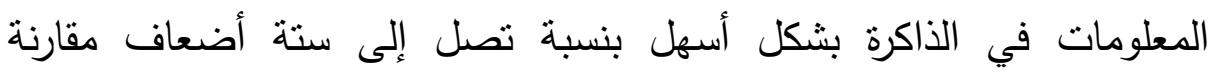
باستخدام النصوص النقليدية. (TD, 2015) ويعد الإنفوجرافيك أحد أكثر الأساليب البصرية المستخدمة في التعليم والتعلم ، فعن طريق التتوع في الأثكال البصرية التي يقدمها والقدرة على تركيز المعلومات في حيز صغير يستطيع المتعلم قراءة المعلومات بوقت أقل وبثكل فلئل Siricharoen \& ( مركز مقارنة بقراءة النصوص والصور النقليدية. (Siricharoen , 2015

يدعم الإنفوجرافيك بشكل كبير العرض المرئي للمعلومات ، فمن خلال التصور يحصل المتعلم على فرصه أكبر لإظهار فكرته والتفكير بالمعنى المقصود لتنظيم عملية التفكير الخاصة بهل ، وبالتالي تصبح المعلومات أكثر وضوحا في عقله.(Ozdamlı et al , 2016)

ولقد انتشر استخدام الإنفوجرافيك كثكل من أنتكال عرض المعلومات

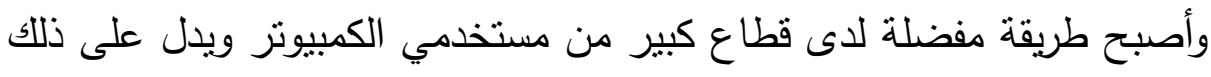

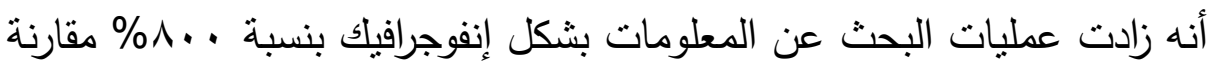

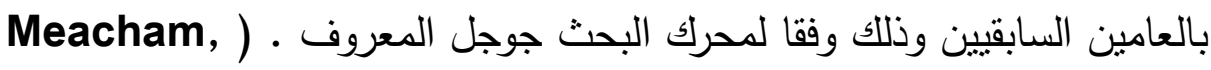
(2015 
ويتميز الإنفوجرافيك بالجمع بين الجانبين اللغوي وغير اللغوي من خلال الجمع بين النصوص والصور والرموز ، وذللك يسهم بشكل كبير في جذب انتباه المتعلم لمشاهدة المحتوى التعليمي والتفكير في عناصرة وكذلك وعرض وتوصيل كميات اكبر من المعلومات بصورة مبسطة وهذا أدى إلى انتشاره بين جميع الاوساط التعليمية وغير التعليمية في عرض وتلخيص البيانات والمعلومات

.(Locoro, 2017)

أثتتت عديد من الدراسات التي تتاولت دور الإنفوجرافيك في العملية التعليمية أهمية استخدامها وتوظيفها في المواقف التعليمية المختلفة منل دراسة (لولوه الدهيم، 19 • ب) التي أوصت بتدريب المعلمين وتتجيعهم على استخدام الإنفوجرافيك وتوظيفه في الفصل الدراسي ، ودراسة (Ozdamlı, 2016) التي أوصت باستخدام الإنفوجرافيك بغرض تسهيل عرض المادة العلمية في المحاضرات وزيادة عددها داخل الكتب الدراسية ، ودراسة (عادل عبدالرحمن ،

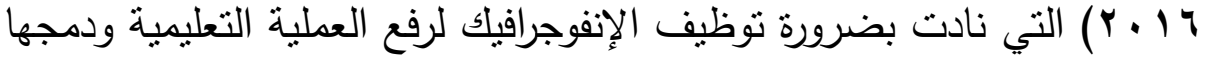
داخل الوحدات التعليمية لأهميتها الكبيرة النفسية والتربوية ، ودراسة (محمد سالم، 17 • P التي تقترح البحث عن طرق جديدة لتوظيف الإنفوجرافيك في المواقف التعليمية بغرض تسهيل واختصار وقت التعلم وضمان بقائها في الذاكرة طويلة المدى ، كما أظهرت نتائج دراسة (Rezaei \& Sayadian, 2015) أن استخدام الإنفوجرافيك يزيد من فرص استخدام الانثطة التعاونية داخل الفصل الدراسي ويجعل التعلم أكثر منعة ويزيد من قدرتهم على البحث في المشكلات التعليمية والقيام بالانشطة التي تسهم في حل تلاك المشكلات مما يزبد من قدراتهم على تحمل مسئولياتهم في عملية التعلم. وترى (Jabr, 2016) أنه لمواجهة الكم الكبير من المعلومات الذي كهي يتم تحديثه بشكل أسرع كثثرا من أبي وقت مضى يجب على التربويين استخدام أدوات جديرة بهذا وهو ما يتوفر باستخدام الإنفوجرافيك ، فالإنفوجرافيك بما يتميز 
به من خصائص عديدة منل تجميع اكبر كم من المعلومات في حيز صغير وبشكل ملخص، يدفع المتعلمين بشكل تلقائي للبحث عن المعلومات وانتقائها وعرضها بأثكال فنية كما يرونها في فصولهم وكتبهر الدراسية ، وبالتالي اكتساب جانب كبير من الوعي المعلوماتي لمواجهة الكم الكبير من المعلومات المعروضة

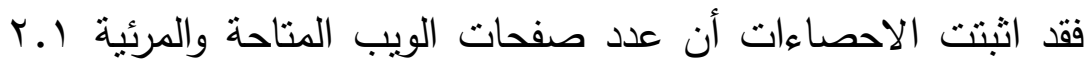
مليار صفحة بنمو زاد بنسبة .10 \% في خلال أعوام قليلة (أحمد فرج، ه · r) ، ونتيجة لهذا الكم الهائل من المعلومات التي تنزايد بشكل يومي فأنه لابد المستخدمين وخصوصا المتعلمين من إمتلاك القدرة على اختيار وتحديد

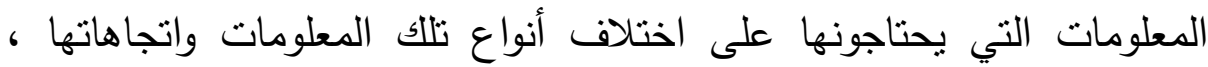
وبالتالي تظهر الحاجة إلى وجود القدر المعقول من الوعي المعلوماتي ليصبحو

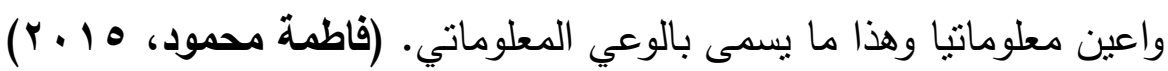
يمنل الوعي المعلوماتي قدرة المتعلم على تحديد المعلومات التي يحتاجها وتحديد مصادرها ثم تقييم تلك المعلومات واستخدامها لتحقيق الأهداف

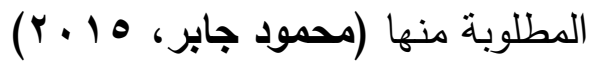
وقد اوضحت نتائج دراسة (أيمن مصطفى، 10 ب. Y) مجموعة من القدرات التي ينبغي اتباعها للحصول على المعلومات وتقييمها مثل تحديد صلاحية المعلومات وتقييم دقتها وشموليتها والقدرة على تلخيصها وتتظيمها والحصول على النتائج المطلوبة وتبرز أهمية الوعي المعلوماتي في اكساب المتعلمين القدرة على حل المشكلات التعليمية التي تواجههم ، من خلال اكتشاف المعلومات عند الحاجة إليها وتحديد مكانها وكيفية الوصول إلى تللك المعلومات ، ويعد توظيف تقنيات المعلومات مؤشر كبير لزيادة كفاءة التعلم والوعي المعلوماتي. (شاكر عبدالعظيم

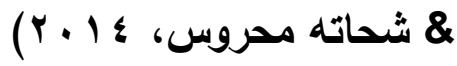


فالوعي المعلوماتي يمنل الاساس في تطوير مهارات التعلم الذاتي والتعليم المستمر مدى الحياة ، وذلك حتى يتمكن المتعلمون من استخدام تقنيات البحث عن المعلومات وتحليلها وتقويمها وتحديد ما يحتاجونه منها واستخدامها وتوظيفها

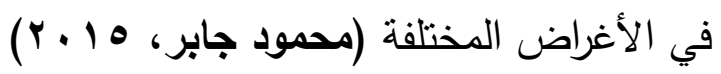

وبالتالي فإن النظرة إلى التعليم لابد أن تتغير لتخدم المجتمع المعلوماتي

لمتضخم المعرفة ، إلا أن الواقع التعليمي الحالي لا يحقق هذا ، فقد اثتت الدراسات عدم وجود أطار أو أسلوب يحدد كيفية التدريب والتعليم للحصول على لئ المعلومات والاستفادة منها ، كما أنه لايوجد مناهج مفعلة لتعليم المهارات المعلوماتية وإذا وجدت فهي مقررات للحاسب الآلي فقط ، وبالتالي يوجد نقص له في المهارات المعلوماتية وقلة الوعي المعلوماتي لدى الطلاب في مراحل التعليم

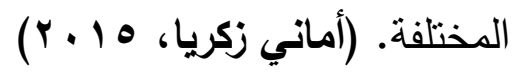
ويؤكد ما سبق نتائج عديد من الدراسات التي تناولت الوعي المعلوماتي

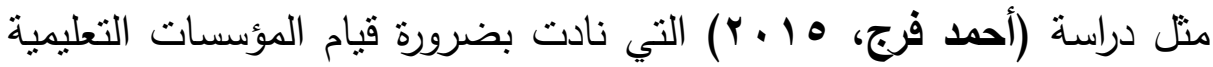
بالتوسع في البرامج التعليمية المتعقلة بكفاءة الوعي المعلوماتي والاهتمام بالموارد

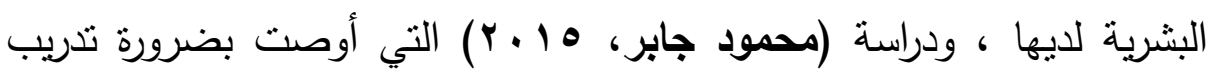
المعلمين على المهارات المعلوماتية وكذلك تقويم الوعي المعلوماتي لطلاب

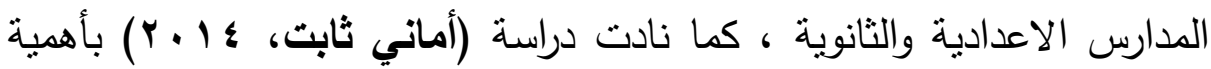
نشر الوعي المعلوماتي بين طلاب الجامعات أنه أساس للتعلم مدى الحياة

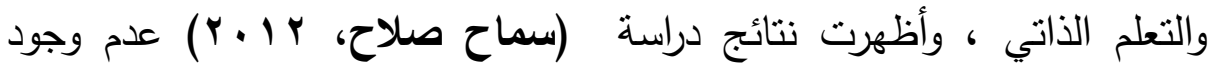
مناهج لتعليم المهارات المعلوماتية في مصر فهي تقتصر على الحاسب الآلي فقط وكذلك افتقاد المقررات الدراسية التي تشجع الطلاب على البحث عن المعلومات. كما أظهرت نتائج الدراسات أن طريقة تتظيم المقررات وتدريسها في ظل المقررات التقليدية لا تراعي مستويات السعة العقلية لدى المتعلمين ولا آلية عمل فل 
الدماغ ، على الرغم من أن السعة العقلية تقوم بدور أساسي في تجهيز ومعالجة المعلومات من خلال انتقال المعلومات إلى الذاكرة الحسية ثم إلى الذاكرة قصيرة

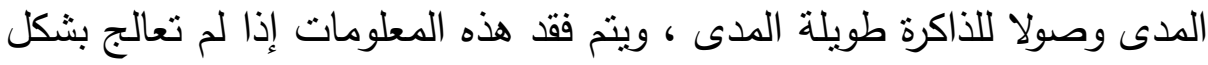

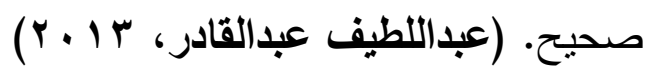

وبالتالي فإن السعة العقلية أحد العوامل الأساسية في معالجة المعلومات فهي تعني الحد الاقصى من الوحدات المعرفية التي يستطيع المتعلم التعامل معها وتتاولها في وقت واحد انثاء معالجة المعلومات ، ويعد أي أرهاق للسعة العقلية أو تحميلها فوق قدرتها العامل المشترك من عدة عوامل تسبب صعوبات تعليمية للمتعلمين من حيث تخزين المعلومات وانتقالها واسترجاعها مما يؤدي لانخفاض في الاداء التعليمي والقدرة على حل المشكلات. (محمد الخطيب، ؛ 1 ـ ب) وقد تتاولت عديد من الدراسات بمراعاة السعة العقلية في جميع المواقف وهات

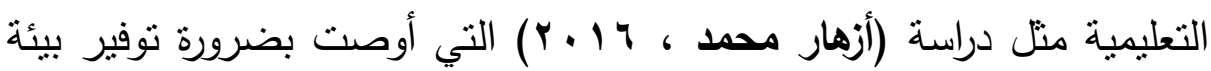
تعليمية بعيدة عن الضغوط التي تساعد على زيادة السعة العقلية من خلال الاستقرار النفسي وكذلك الاستفادة من عامل السعة العقلية وتطبيقة على القائعين بالعملية التعليمية ، ودراسة (محمد الخطيب، \& ا ـ ب) التي نادت بضرورة مراعاة واضعي الكتب الدراسية للسعة العقلية للطلاب وأيضا ضرورة مساعدة المعلمين للطلاب في التغلب على كم المعلومات التي تعوق السعة العقلية ، كما أوصت

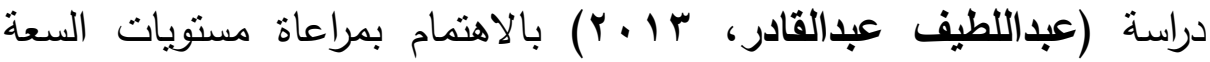
العقلية في المقررات الدراسية وكذلك تدريب المعلمين عليها لما لها من أثر في بهاه زيادة التحصيل ونمو الاتجاهات في ضوء نلك المستويات. مشكثة البحث نبع الإحساس بمشكلة البحث من عدة مصادر أساسية كما يلي : 
- أنتائج وتوصيات البحوث والدراسات السابقة : التي أوصت بضرورة امتلاك المتعلمين مهارات الوعي المعلوماتي مثل دراسة

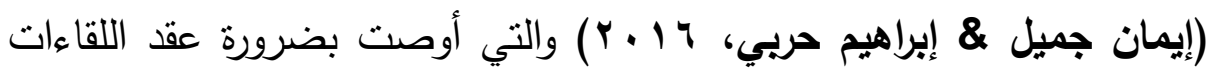
الدورية مع الأكاديمبين بهدف اثراء الوعي المعلوماتي لديهم وتطوير خبراتهم

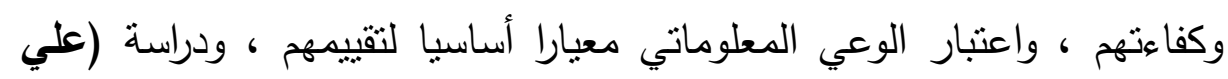

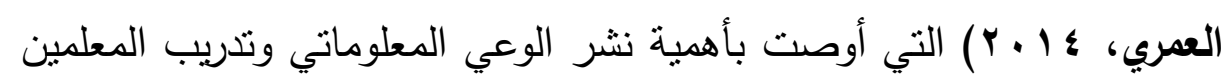

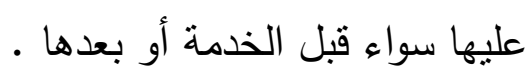
ومن ناحية أخرى أظهرت عديد من الدراسات وجود ضعف في المقررات الحالية

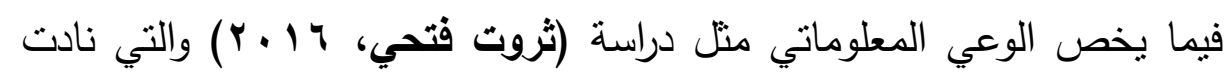
بأهمية إدراج الوعي المعلوماتي ضمن المقررات الدراسية في المراحل ما قبل

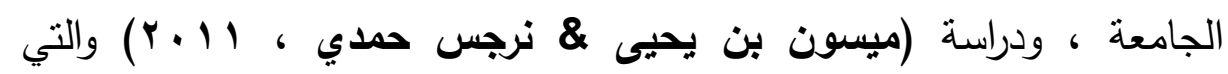
أظهرت نتائجها وجود بعض الخلط لدى الطلاب في مفهوم الوعي المعلوماتي

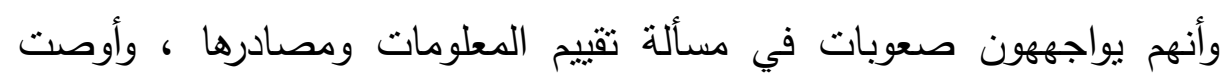

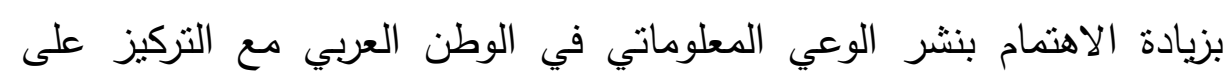
طلاب الجامعة. r- الاراسة الاستكشافية لإختبار الوعي المعلوماتي:

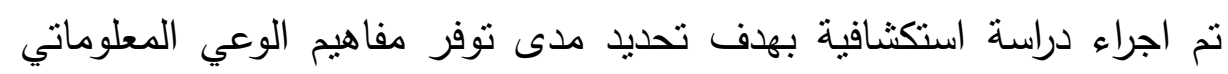

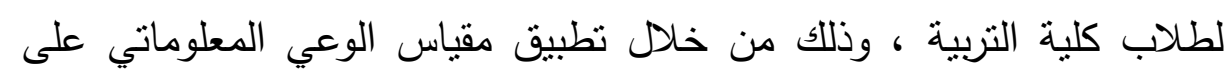

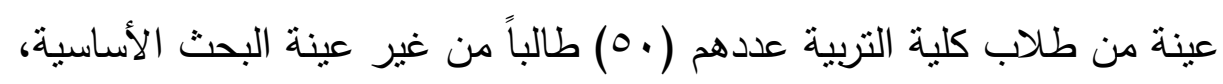
وقد اسفرت نتائج الدراسة الاستكثافية عن تدني مستوى معظم أفراد العينة في المفاهيم المرتبطة بالوعي المعلوماتي حيث تراوحت النسبة المئوية لدرجاتهم في الإختبار مابين 0ץ\% إلى به\% ، ، مما يؤكد للباحث الحاجة الضرورية لتتميته

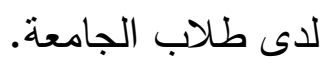


في ضوء ما سبق وحيث أن عملية التعليم بشكل عام تحتاج إلى أساليب تدريسية تساعد على تتمية مستوى الوعي المعلوماتي وتسهم في علاج الفروق الفردية بين المعلمين في السعة العقلية ، ومن ثم فإن البحث الحالي يسعى لمحاولة التصدي لهذه المشكلة من خلال أثز استخدام نمطي الإنفوجرافيك في

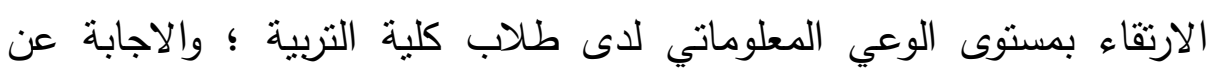
السؤال الآتي: - الآثاء

ما أثر نمطي الإنفوجرافيك (الثابت ، المتحرك) في تثمية الوعي المعلوماتي في ضوء السعة العقلية (مرتفع ، متوسط ، منخفض) لالى طلاب كلية التربية ؟ يتفرع من السؤال الرئيس الاسئلة الفرعية الآتية:

ا- ما أثز الإنفوجرافيك في تتمية الوعي المعلوماتي لدى طلاب كلية التربية ؟ r- ما أثز نمطي الإنفوجرافيك (الثابت، المتحرك) في تتمية الوعي المعلوماتي لاى طلاب كلية التربية ؟ ץ- ما أثز الإنفوجرافيك في تتمية الوعي المعلوماتي لاى طلاب كلية التربية ذوي السعات العقلية المختلفة ؟ ع- ما أثز التفاعل بين نمطي الإنفوجرافيك (الثابت ، المتحرك) وبين (مستويات من السعة العقلية) في تتمية الوعي المعلوماتي لدى طلاب كلية التربية ؟ أهمية البحث: نبعت أهمية البحث الحالي من الجوانب الآتية:

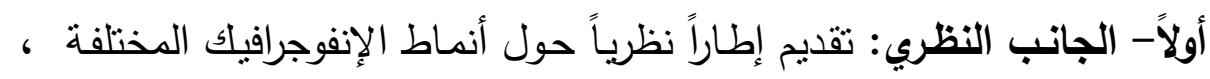
والمفاهيم الأساسية المرتبطة بالسعة العقلية. ثانياً- الجانب العملي التطبيقي: إتاحة الفرصة للقائمين على العملية التعليمية بتصنيف المتعلمين حسب استعداداتهم العقلية وذلك من خلال استخدام المقاييس النفسية ، مما يسمح باستخدام أنماط الإنفوجرافيك المناسبة لكل فئة منهم ، كذلك 
الارتقاء بمستواهم في مجال الوعي المعلوماتي مما يساعد في زيادة جودة المنتج التعليمي ويدعم العملية التربوية.

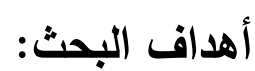
هدف البحث الحالي إلى الارتقاء بمستوى الوعي المعلوماتي لدى طلاب كلية التربية من خلال الكثف عن: ا - أثر الإنفوجرافيك في تتمية الوعي المعلوماتي لدى طلاب كلية التربية. r- اثر نمطي الإنفوجرافيك (الثابت - المتحرك) في تتمية الوعي المعلوماتي لدى طلاب كلية التربية. r- الفروق بين طلاب كلية التربية من ذوي السعة العقلية المختلفة في إختبار الوعي المعلوماتي. ع- التأثنر المتبادل بين متغير نمط الإنفوجرافيك (الثابت والمتحرك) ومستوى السعة العقلية (مرتفع ، متوسط ، منخفض) في تتمية الوعي المعلوماتي لدى لإلى طلاب كلية التربية حدود البحث: التزم البحث الحالي بالحدود الآتية : 1- حدود محتوى : تمثلت في مفاهيم الوعي المعلوماتي والتي يقيسها إختبار الوعي المعلوماتي (أماني زكريا، 10 • ب) وتتضمن القدرة على تذكر معلى ملومات ومفاهيم، القدرة على حل المشكلات المعلوماتية، القدرة على تطبيق المعارف. r- حدود بشرية : طلاب الفرقة الثالثة كلية التربية ، جامعة المنيا.

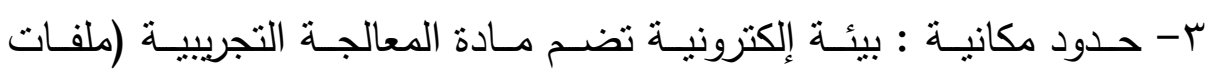
الإنفوجرافيك الثابت وملفات الإنفوجرافيك المتحرك).

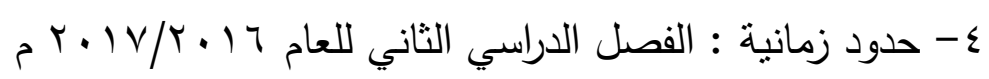


سعى البحث الحالي إلى التحقق من صحة الفروض الآتية:

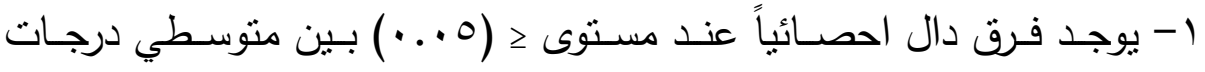

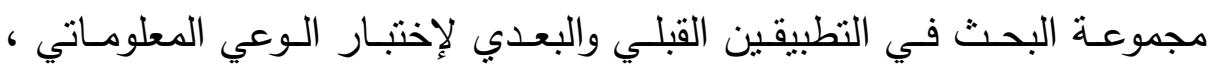
لـالح التطبيق البعدي.

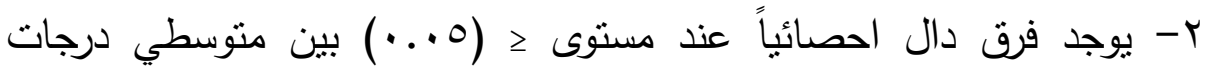
مجموعتي البحث التي استخدمت الإنفوجرافيك الثابت والمتحرك ، في التطبيق البعدي لإختبار الوعي المعلوماتي لصالح مجموعة الانفوجرافيك المتحرك.

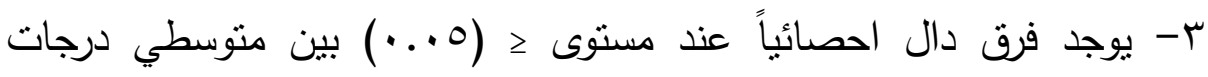
مجموعات البحث في التطبيق البعدي لإختبار الوعي المعلوماتي ترجع إلى لئ اختلاف مستوى السعة العقلية بينهم. ع - يوجد فرق دال احصائياً عند مسنوى > (0. . ) بين منوسطي درجات مجموعات البحث في إختبار الوعي المعلوماتي يرجع لتأثير التفاعل المنبادل بين نمطي الإنفوجرافيك (الثابت ، المتحرك) ومستويات السعة العقلية لدى لديع

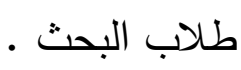
أدوات البحث: أ أدوات القياس:

أ- إختبار الوعي المعلومـاتي (أماني زكريا، 10 • r): تم تصميم هذا الإختبار بهدف قياس مستوى الوعي المعلوماتي ، يتكون الإختبار من ه V مفردة موزعة

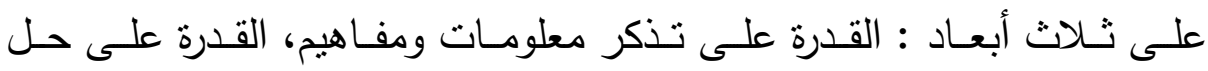
المشكلات المعلوماتية، القدرة على تطبيق المعارف.

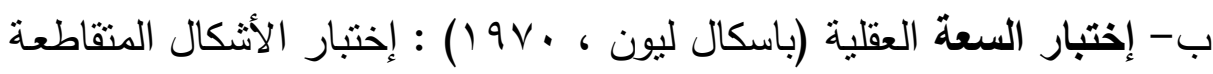
Figural Intersection Test F I T 
السـعة العقليـة ، يتكـون الإختبـار مـن جس فقرة إضـافة إلى 7 فقرات تمهيديـة

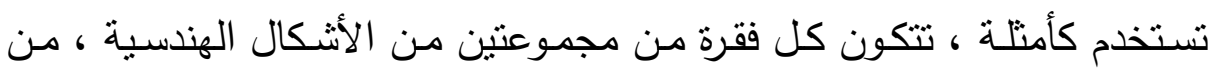
جهة اليمين تكون الأشكال الهندية البسيطة منفصلة ومن جهة اليسار تكون الأثـكال الهندسية متداخلـة مكونـة شكل معقد ، والمطلـوب مـن المتعلم تحديد المنطقة التي تتنرك فيها جميع الأشكال المتداخله ومن ثم نزداد الفقرات صعوبة كلما زاد عدد الأشكال المتداخلة. r - مادتي المعالجة التجريبية: أ- المعالجة التجريبية الأولى (الإنفوجرافيك الثابت): في تلك المعالجة تم إعداد المحتوى التعليمي للموضوع في هيئة إنفوجرافيك ملفات صور تهدف إلى عرض مفاهيم وأبعاد الوعي المعلوماتي. ب - المعالجة التجريبية الثانية (الإنفوجرافيك المتحرك) : في تلك المعالجة التجريبية تم استخدام نفس المحتوى التعليمي السـابق الاشـارة إليـهـ في المعالجـة التجريبيـة الأولـى ويحقـق نفس الاهـداف وباسـتخدم نفس الخطوات ، ولكن نم انتاج الإنفوجرافيك المتحرك في شكل ملفات فيديو . مصطلحات البحث: 1- إنفوجرافيك (Infographic) : يُعرف إجرائياً بأنه مجموعة من النصوص مدمجة بالصور الثابتة أو المتحركة تقوم باختصسار وعرض كم من المعلومات بطريقة جذابة بهدف تتمية الوعي المعلوماتي لدى مجموعة البحث. أ. الإنفوجرافيـك الثابـت : مجموعـة من النصوص المدمجة بالصـور والاثكال الثابتة ، يتم انتاجها في شكل ملفات صور رقمية ، تقوم باختصار وعرض كم مـن المعلومـات بشـل جذاب بهدف تتميـة الـوعي المعلومـاتي لـدى مجموعـة

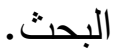


ب. الإنفوجرافيك المتحرك : مجموعة من النصوص المدمجة بالصور والاشكال المتحرك ، يتم انتاجها في شكل ملفات فيديو رقمي ، ثقوم باختصار وعرض كم

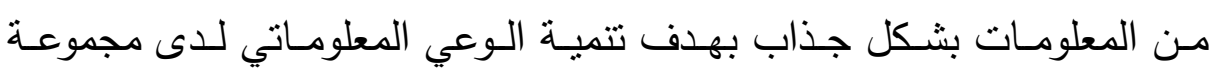
البحث.

r-الوعي المعلوماتي (Information Awareness) : يُعرف إجرائياً بانه امتلاك مجموعة البحث المعلومات التي تمكنهم من القدرة على حل المشكلات

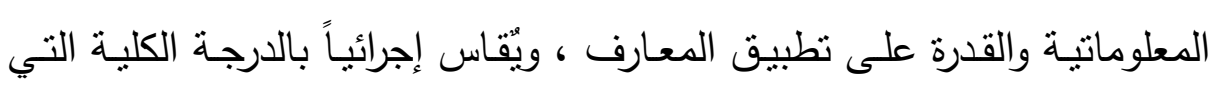
يحصل عليها المتعلم في إختبار الوعي المعلوماتي المطبق في البحث الحالي. r-السعة العقلية (Mental Capacity) : يتبى البحث الحالي تعريف (جان

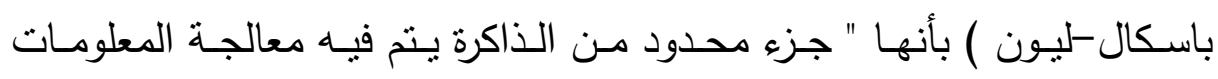

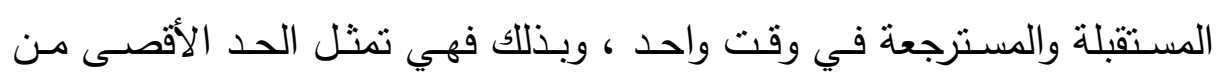

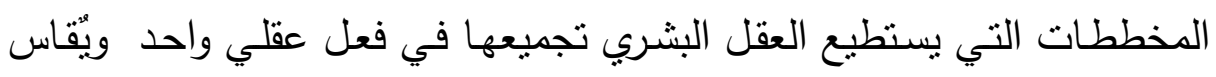

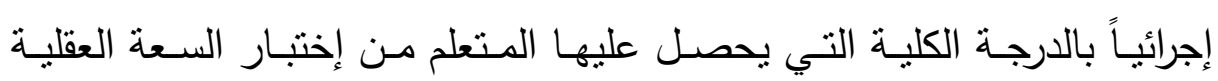

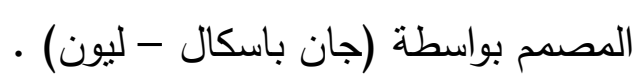

الإطار النظري والادراسات السابقة:

تضمن البحث الحالي المحاور رئيسية الآتية: الانفوجرافيك ؛ الوعي المعلوماتي ؛ السعة العقلية ، والذي سوق بتم تتاولهم بشئ من التفصيل:

$$
\text { أولاًَ- المعنى الأول - الإنفوجرافيك : للغوي للإنفوجرافيك: }
$$

مصلح الإنفوجرافيك ترجمة للمصطلح الاجنبي (Infographic) والذي يتكون من مقطعين الأول (Information) بمعنى معلومات ، والثاني (Graphic) ويعني التصويري ، وبالتالي فالترجمة الحرفية له تعني البيانات التصويرية ويمكن 
أن بطلق عليها اسم التصميم المعلوماتي ويمكن فهمها بأنها تصوير للمعلومات بطريقة مشوقة تجذب انتباه المتلقي. (حماده محمد، 10 ـ ب). ثانياً - المسميات المختلفة للإنفوجرافيك:

أوردت المراجع العربية عديد من المسميات لمنتج إنفوجرافيك ، مثل : التجسيد البصري للبيانات ، العمارة المعلوماتية ، تصميم المعلومات والبيانات التصويرية التفاعلية وكلها تعني عرض معلومات معقدة بسرعة ووضوح (عبدالرؤوف محمد

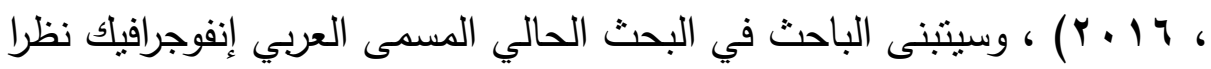

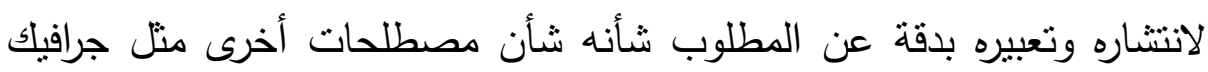
graphic ثالثا - تعريف الإنفوجرافيك:

تعددت الأدبيات التي تتاولت مفهوم الانفوجرافيك مثل (Lee, 2016) و(Hezaei, 2015) و (Harvey, 2014) ، ولكنها أجمعت على مايلي:

$$
\text { هي وسيلة ومكون تعليمي بصري }
$$

تعتمد على إعادة انتاج المعلومات من خلال اختصارها وعرضها بشكل

موجز

يوجد تفاعل بين عنصري النص والرسومات بشكل لايستطيع احدها

$$
\text { الاستغناء عن الآخر }
$$

هتم ترتيب النصوص والرسومات بشكل منطقي ومنظم يرتبط بالهدف الرئيس

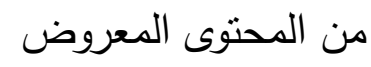

$$
\text { رابعاً - انواع الإنفوجرافيك : المعتئ }
$$

يرجع تعدد تعريفات الإنفوجرافيك إلى تتوع أشكال وأنواع الإنفوجرافيك طبقا لوجهة نظر من صنف هذه الأنواع ، ومن خلال استعراض العديد من المراجع 


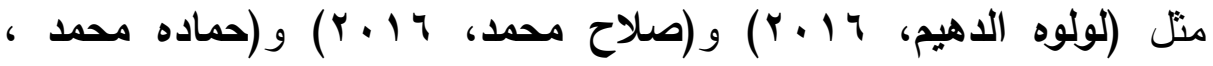

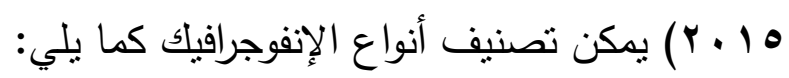

\section{أنواع الإنعوحرافيك}

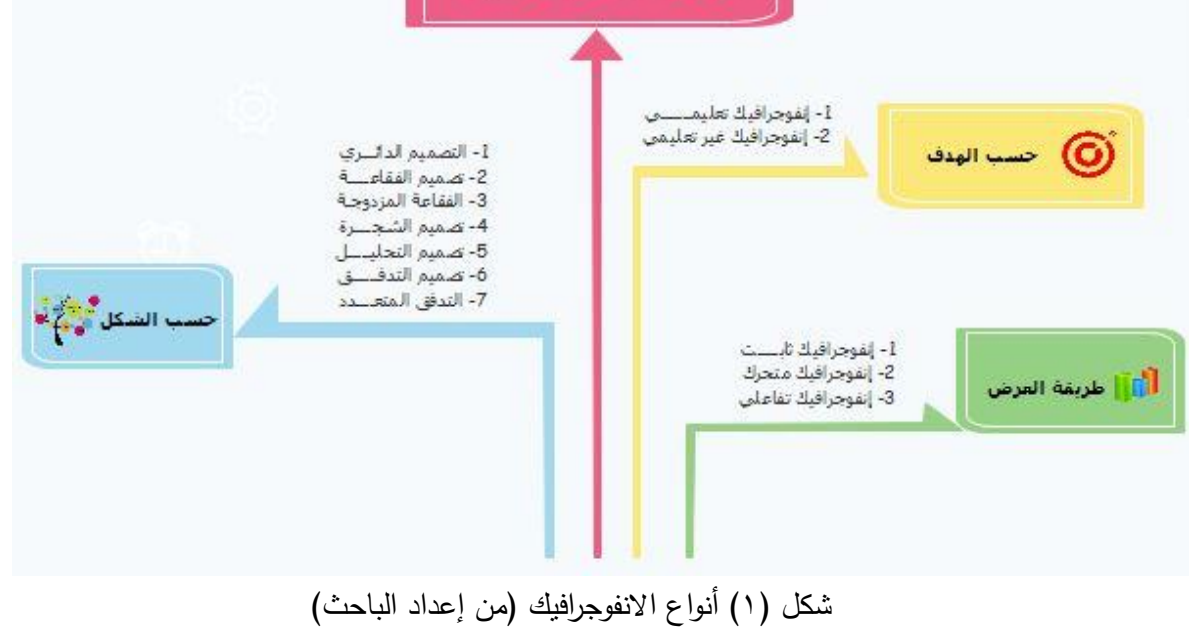

: 1

إنفوجرافيك تعليمي : يهدف لعرض محتوى وفق أهداف تعليمية ويندرج أسفله الإنفوجرافيك المدرسي والديني والتقافي والتاريخي والصحي. إنفوجرافيك غير تعليمي : يهدف لعرض محتوى بغرض دعائي مثل

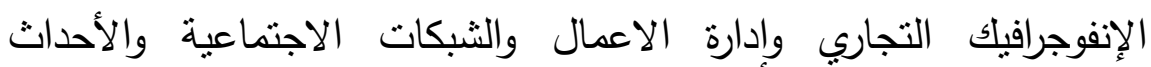
الرياضية وعرض المنتجات. من حيث الهدف من الإنفوجرافيك اعتمد البحث الحالي على الإنفوجرافيك التعليمي وذللك نظرا لأنه يتتمي للبحوث التربوية. 


\section{r - من حيث الثكل والتخطيط:}

الائري: يعتمد على وجود عنوان في مركز الدائرة ، ويتم كتابة معلومات في محيط الدائرة ، ويستخدم لعرض فكرة في المركز وتفاصيلها في المحيط.

الفقاعة: يتم كتابة الكلمة أو الثئ في دائرة مركزية ، ويتم كتابة الخصائص أو مميزات سواء على شكل نصوص أو رسومات في دوائر حول الدائرة المركزية. الفقاعة المزدوجة: تستخدم للمقارنة بين شيئين ، يوضع عنوان كل شئ في دائرة مركزية وبالتالي تكون لدينا دائرتين ، وحول كل دائرة مركزية دوائر متفرعة توضح خصائص هذا الثـئ. تصميم الثجرة: تستخدم لعرض تصنيفات وتقسيمات نابعة من فكرة رئيسية ، فيتم وضع الفكرة في مركز الثجرة ، وتتفرع الأفكار من تلك الفكرة من

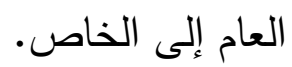
تصميم التحليل: يستخدم في شرح مكونات شئ معين ، فيتم كتابة اسم الثئ ثم تتفرع منها خطوط كل خط يكتب فيه الاجزاء الرئيسية لهذا الثئ. تصميم التذفق: يستخدم لشرح احداث متتابعة وخطوات السير في العمليات ، وتستخدم الاسهم في شرح اتجاه تتفيذ العمليات . تصميم التدفق المتعدد: يستخدم في توضيح العلاقة بين السبب والنتيجة ، حيث تستخدم الاسهم والأشكال في توضح النتيجة التي تتتج عن السير في خطوات معينة وقد تتوعت التصميمات المستخدمة في البحث الحالي وذلك نظرا لنتوع المعلومات المطلوبة من اجل اكساب الوعي المعلوماتي. r - من حيث طريقة العرض : 
إنفوجرافيك ثابت: عبارة عن صورة ثابتة قد تككن مطبوعة على ورق أو منشورة بشكل رقمي على شبكة الانترنت أو معروضة باستخدام الكمبيوتر

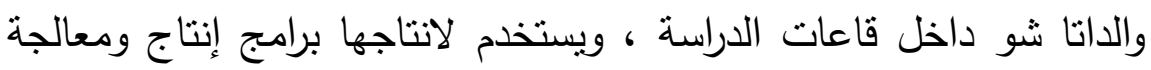
الرسومات والصور الرقمية ، ويكون المنتج النهائي صورة رقمية ثابتة. إنفوجرافيك متحرك: عبارة عن مجموعة من الأشكال والتي يتم تحريكها أمام المشاهد بشكل تتابعي يجذب الانتباه ، ويستخدم لانتاجها برامج انتاج ومعالجة الرسومات والصورة الرقمية لانتاج العناصر الرسومية كخطوة أولى بلى بهاه ثم تستخدم برامج مونتاج الفيديو الرقمي لتحريك تلك الأشكال ، ويكون المنتج النهائي ملف فيديو رقمي. إنفوجرافيك تفاعلي: هي تصميمات ثابتة أو متحركة يستطيع المستخدم

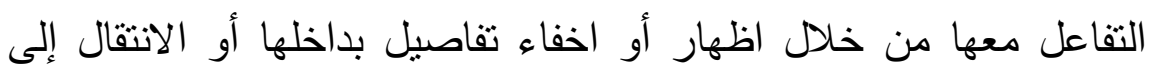
رسومات وأثنكال أخرى مرتبطة بها ، وتنتخدم لانتاجها برامج إنتاج

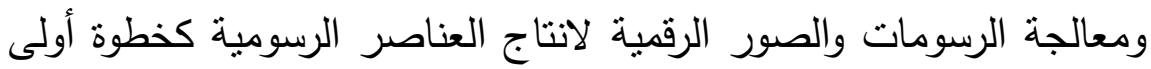
، ثم تستخدم برامج إنتاج الوسائط المتعددة في برمجة التفاعل ، ويكون المنتج النهائي ملف تتفيذي. وقد اقتصر البحث الحالي على استخدام الإنفوجرافيك الثابت والإنفوجرافيك المتحرك وتم استبعاد الإنفوجرافيك التفاعلي نظرا أن الهدف الإف من البحث الحالي قياس تأثنر عناصر الإنفوجرافيك وضغطها على الذاكرة العاملة من اجل معرفة الفروق في اكتساب المعلومات وفق السعة العقلية ، أما الإنفوجرافيك التفاعلي فهو يتميز بخاصية تمدد وانكماش المعلومات وبالثالي يمكن للمتعلم تطويع عدد الأشكال والعناصر المتجاورة بسهولة وبالتالي لن تظهر الفروق في السعة العقلية اذا تم استخدام الإنفوجرافيك التفاعلي. 


\section{خامساً - مكونات الإنفوجرافيك :}

على الرغم من تعدد أثكال الإنفوجرافيك إلى أنه توجد عناصر مشتركة وموجودة

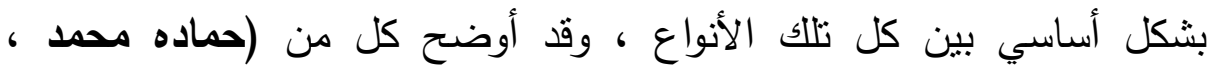

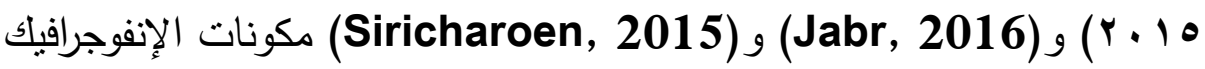
كما بلي : 1 - المكونات التعليمية للإنفوجرافيك : المحتوى : ويتكون من الحقائق والمفاهيم والاحصاءات والمراجع. الترمبز :تحويل المحتوى لأشكال وعناوبن نصية لاختصار وقت القراءة

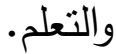
المعرفة : الناتجة من دمج جميع المكونات التعليمية للإنفوجرافيك.

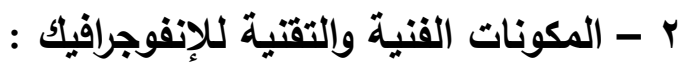

العناصر المرئية: المكونة للأشكال البصرية وهي الألوان والرسوميات والأثكال الرمزية والخرائط والنصوص والاطارات .

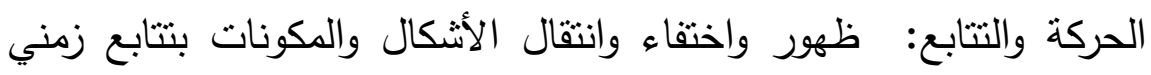
محدد لاغراض الابهار والتدقيق. القابلية للمشاركة : انتاجه في صورة ملف واضح التفاصيل وصغير الحجم يمكن رفعه على شبكه الانترنت او طباعته او عرضة بشكل مباشر . • الاتصال البصري : الناتجة عن دمج جميع المكونات الفنية للإنفوجرافيك. سادساً - معايير تصميم الإنفوجرافيك : لكي يحقق الإنفوجرافيك الغرض التعليمي من وجوده مع مراعاة الفنيات في الانتاج لابد من اتباع مجموعة من الارشادت التي توضح كيفية التصميم وقد تناولت العديد من الدراسات معايير تصميم الإنفوجرافيك ومن تلك الدراسات : 
دراسة (Kibar \& Akkoyunlu , 2014) والتي كان هدفها التعرف على اكثز التصميمات فاعلية للإنفوجرافيك كأداة تعليمية ، حيث تمت المقارنة من حيث المكونات المرئية والنصوص والعناوين والألوان والخطوط وتنظيم المعلومات ، اوضحت نتائج الدراسة أن تتظيم المعلومات والخطوط والألوان هي ولني الاكثر أهمية للمتعلمين. ودراسة (Noh, 2015) التي هدفت إلى الكثف فاعلية الإنفوجرافيك في تسهيل عملية التعلم ، وتوصلت نتائجها إلى تميز الإنفوجرافيك بامكانية تشجيع المتعلم على فهم أفضل للمعلومات بشرط احتواؤه على تصميمات جيدة وألوان جذابه. وأيضا دراسة (Dai et al, 2014) والتي كان من ضمن أهدافها استعراض ناريخ وتطور الإنفوجرافيك ودوره كأداه فعالة في مجالات الاعلام

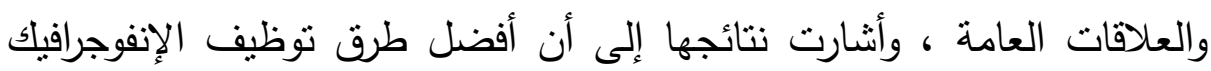
لابد أن تتم بالبدء بالموضوع المناسب المقنع بصرياً من حيث سيكولوجية الألوان

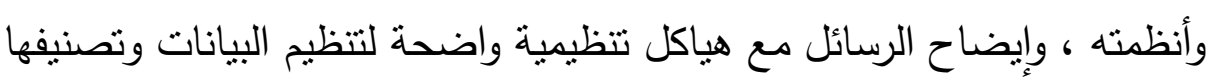

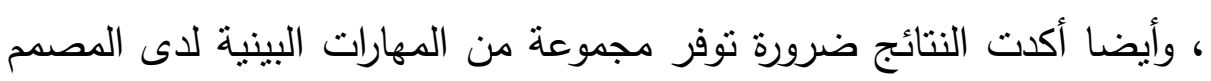
وهي مهارات التصميم المرئي والمهارات البحثية والفنية. بمراجعة الدراسات السابقة التي وضعت معايير فنية وتربوية لتصميم الإنفوجرافيك وأهمها دراسة ، وأيضا مراجع أخرى تتاولت معايير التصميم مثل

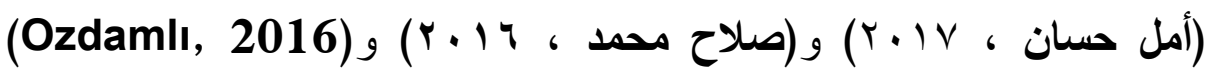
و) و (عبدالرؤوف محمد، 17 (Thompson, 2016) أمكن تلخيص معايير التصميم وإنتاج الإنفوجرافيك على النحو التالي: 1 - المعايير التريوية لانتاج الإنفوجرافيك الإنيك • الهـف التعليمي: واضح ومحدد ، يرتبط بالمحتوى وخصائص المتعلمين

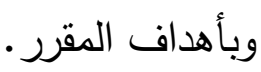


المحتوى: صحيح علميا ولغويا ، واضح وموجز وخالي من التفاصيل الزائدة ، يرتبط بالاهداف التعليمية ، معد بطريقة تسهل من تمثيله بصريا. خصائص المتعلمين: يناسب المستوى العقلي وسن وخبرات المتعلمين. الحيز: قلة حجم الإنفوجرافيك وقلة التفاصيل مع عدم الاخلال بتركيز المعلومات.

الوضوح: سهولة فهم الإنفوجرافيك بما بشمله من عناصر رسومية ونصية. الشمولية: عرضه لكافة عناصر الفكرة بشكل كامل ومختصر العنوان: ملفت للانتباه ويكون مرتبط بالأهداف والمحتوى. r - المعايير الفنية والتقنية لانتاج الإنفوجرافيك : البساطة في التصميم : يعرض فكرة واحدة بشكل متكامل ، غير مزدحم وبعيد عن المبالغة في الابهار الفني. الاخراج: عناصره منرابطة وبها علاقة واضحة ، منوازن في عرض العناصر ويتتاسب حجمه مع الفكرة الرئيسية ، يتميز بالابتكار ، تكبير حجمه لايقلل جودته. الخطوط : استخدام نوع وحجم خط مناسب وسهل القراءة ، ويتتوع في احجام وألوانه وفقا للغرض منه.

الألوان: الاستخدام الدال للألوان بحيث تكون موظفة بشكل واقعي وعلمي ، والنظام اللوني المستخدم يربط الافكار البصرية ويشد انتباه المشاهد ، مع وجود تباين بين الثكل والأرضية ، الخلفية ذات الوان محايدة ، براعي

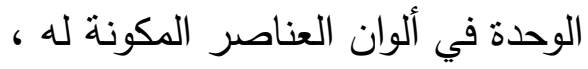
الرسوم والأشكال: استخدام رسومات مناسبة لتوضيح الفكرة وتحقق الهدف ، تجنب الافراط في استخدامها ، استخدام أثنكال سهلة الادراك.

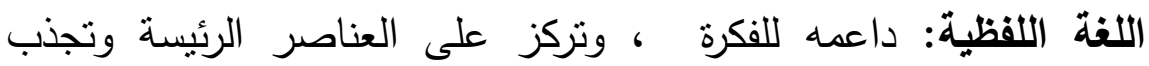
الانتباه. 
التخطيط: استخدام قالب تصميمي وهياكل بنائية يتتاسب مع طبيعة الاهداف والمحتوى ، مراعاة التتاسب في الحجم بين الأشكال والصور وقدر البيانات

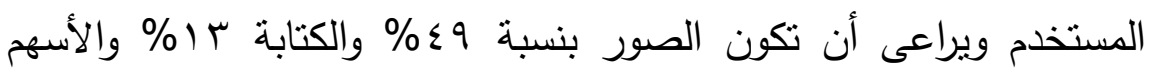

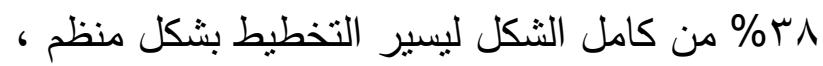
الحركة: يتيح التقديم والتأخير والتحكم في سرعة العرض ، تتتاسب مع كمية المعلومات المعروضة ومع مستوى المتعلمين ، تجنب الافراط الذي يؤدي لتشتت الانتباه. التفاعلية: يتيح عناصر نشطة تمكن من الانتقال لأشكال أخرى ، العناصر النشطة ظاهرة وواضحة ومدمجه بشكل كامل مع الإنفوجرافيك ، عدم الافراط في استخدامها. البيانات الشخصية: موجودة أسفل التصميم لكي يتمكن المتعلم من التواصل مع الكيان المسئول عن الإنفوجرافيك.

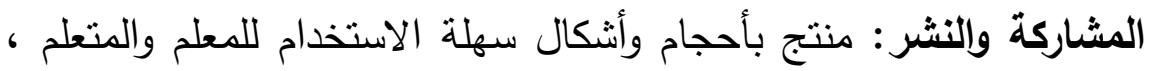
وتصلح للتعامل والنشر على البيئات والأجهزة الإلكترونية المختلفة التي قد بـان

$$
\text { تستخدم في عرضه. }
$$

وقد تم مراعاة هذه المعايير في الانتاج بما يتتاسب وطبيعة كل نمط من الأنماط سابعاً - أهمية الإنفوجرافيك: نظرا للمزايا التربوية والفنية والتقنية للإنفوجرافيك فإن له دورا كبيرا وأهمية بالغة عند استخدامه في التعليم وعند توظيفه في المواقف التعليمية المختلفة ، وقد تتاول كل (عبدالرؤوف محمد، 17 . Meacham, 2015) و الأهمية التربوية للإنفوجرافيك على النحو الآتي: يتوافق مع عمل العقل البشري ، فالعقل البشري يستوعب الكلمات والنصوص بشكل أبطأ وبتحميل أكثر من مشاهدة النصوص المدمجة داخل الصور . 


$$
\begin{aligned}
& \text { يساهم في فهم المجردات بصورة أوسع. } \\
& \text { استثارة دافعية المتعلمين وحفزهم • } \\
& \text { المساهمة في علاج الفروق الفردية. }
\end{aligned}
$$

سهلة في البقاء في الذاكرة وبقاء أثر التعلم ، وأكثر فاعلية في الفهم. الجمع بين الجانب اللغوي المتمنل في البيانات والجانب الغير لغوي المتمنل في الصور لجذب انتباه المتعلم ويشجع العين على قراءة البيانات بسرعة . استمرار التعلم باستخدام الإنفوجرافيك يكسب المتعلم مهارة انتقاء المعلومات الهامة ضمن كم كبير من المعلومات. تقديمه للمعلومات بصورة بصرية يجعله ينمي مهارات التفكير البصري. قدرته على تبسيط وتسهيل عرض المعلومات المعقدة مما يحسن الفهر والادراك.

تقدم للمتعلم الفرصة للمقارنة والتأمل وتمده بسبل التفكير الاستتاجي. اتاحة التفاعل بين المتعلم وأقرانه من خلال مناقثنة المحتوى الذي يعرضهـه. سهل الانتاج وقليل التكلفة.

يساعد على تذكر المعلومات بشكل أفضل ويسهل عملية استيعابها . تتمية القدرات العقلية للمتعلم من ابداع وتفكير وتذكر على المدى البعيد. قابلية تطبيقه على عدد متتوع وكبير من التخصصات العلمية ، وعلى أعمار وخلفيات ثقافية مختلفة. مرن في أساليب وطرق العرض.

سهولة انتشاره ونشره عبر بيئات التعلم وعبر الثبكات الاجتماعية. أداة مثالية لتوضيح شكل الأشياء الغير مألوفة. وقد أكلت عديا من الدراسات أهمية توظيف الإنفوجرافيك في التحصيل وتتمية الاتجاهات الإيجابية في المقررات والمواقف الدراسية المختلفة ومن تلك الاراسات: 
دراسة (عادل عبدالرحمن وآخرون، 17 • ب) والتي هدفت إلى تعرف دور الإنفوجرافيك في العملية التعليمية من خلا الصياغات النتكيلية للنص وعلاقة النص بالصورة، وتوصلت إلى أن الإنفوجرافيك كمثير بصري يتميز بالتكيف الدلالي للمفاهيم وما يتصل بها من معاني وبالتالي أهميته التعليمية في المساعدة على التذكر والفهم.

ودراسة (Ozdamlı, et al, 2016) والتي هدفت إلى قياس اتجاهات

المتعلمين حول استخدام الإنفوجرافيك في مقرر التشريح ، وتوصلت نتائجها إلى أن الإنفوجرافيك أكثر فاعلية وأسهل في بقاء المعلومات في الذاكرة من الطرق التقليدية. ودراسة (صلاح محمد، 17 ـ ب) التي كان هدفها تعرف فاعلية الإنفوجرافيك في تتمية التحصيل في مقرر الجغرافيا ومهارات التفكير البصري ، وكثفت نتائجها عن وجود تحسن في مستوى تحصيل مجموعة البحث التي درست باستخدام الإنفوجرافيك ، وأيضا اثراء عملية التعليم والتعلم بسبب توظيف وسائط

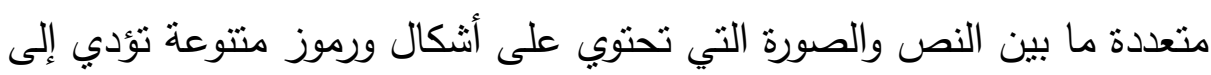
سهولة استيعاب المحتوى.

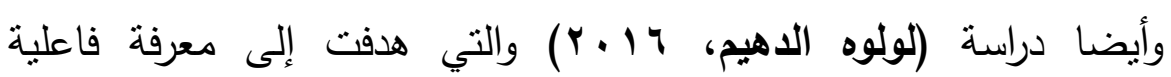
الإنفوجرافيك على تعلم الاداء المهاري والتحصيل المعرفي للوثب الطويل ، اشارت النتائج إلى وجود فروق دالة احصائية لصالح المجموعة التي درست باستخدام الإنفوجرافيك في تعلم مهارات الوثب واداء حركة المشي في الهواء حيث ساعد البرنامج على اثاره اهتمام الطلاب وتحفيزهم على بذل الجهد في التعلم وعدم شعورهم بالملل. ودراسة (Rezaei \& Sayadian, 2015) التي هدفت إلى قياس تأثير الإنفوجرافيك في نحو تعلم قواعد اللغة الانجليزية كلغة ثانية ، وتوصلت إلى أن الإنفوجرافيك يعد اداة فعالة في تعلم اللغات الاجنبية. 
وفي دراسة (حماده محمد ، 10 ب ب) التي هدفت إلى الكثف عن فاعلية استخدام تقنية الإنفوجرافيك لتصميم وانتاج المواد البصرية ، توصلت إلى فاعلية الإنفوجرافيك في اكساب الطلاب كل من المكون المعرفي والأدائي لتصميم وانتاج المواد البصرية.

ودراسة (شيماء محمد، 0 (Y) التي هدفت إلى معرفة اثر استخدام

الإنفوجرافيك على التحصيل في مادة العلوم والاتجاه نحو تعلمها ، وقد اوضحت النتائج فاعلية الإنفوجرافيك في التحصيل والاتجاه والدافعية نحو تعلم مقرر

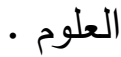

\section{يتبين من عرض الدراسات السابقة ما يلي:}

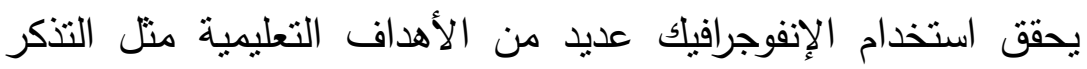
والفهم وبقاء المعلومات والتحصيل والمهارات الرياضية ومهارات التفكير وتعلم اللغات ومهارات انتاج المكونات التكنولوجية يحفز استخدام الإنفوجرافيك المتعلمين ويثير اهتمامهم نحو التعلم بشكل واضح ، وينمي التقكير الإيجابي ، والاتجاه نحو التعلم ، والاتجاه نحو

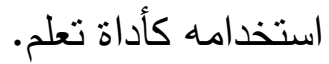

تتوعت أدوات القياس المستخدمة في ثللك الدراسات ما بين الإختبارات المعرفية ومقاييس وبطاقات تقييم الاداء ومقاييس الاتجاه. توجد وفرة في الدراسات العربية والاجنبية التي تؤكد التأثنر الفعال للإنفوجرافيك في العملية التعليمية. تختلف الدراسة الحالية عن الدراسات السابقة في أنها تهرف لتتمية متغير تابع لم يستخدم في تلك الدراسات وهو الوعي المعلوماتي ، وكذلك تراعي الدراسة الحالية اختلاف مستويات السعة العقلية كمتغير تصنيفي لمجموعة البحث. 


\section{المحور الثاني- الوعي المعلوماتي: \\ أولاًا- مفهوم الوعي المعلوماتي:}

يعد بول زوركوسكي P.Zurkowski أول من استخدم مصطلح الوعي الوي

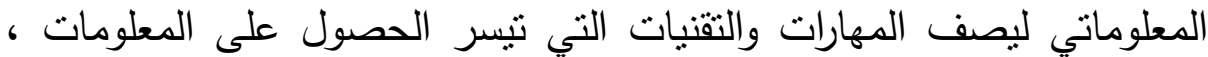

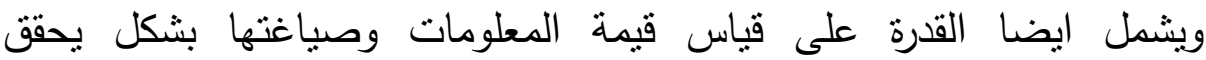
الاحتياجات المعلوماتية ويوفر حلولا للمشكلات المتاحة. (أماني زكريا، 10 + ب)

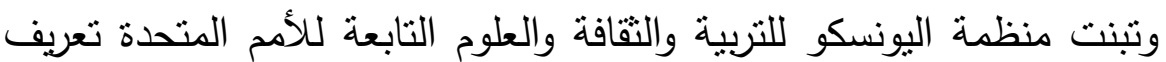
الوعي المعلوماتي بأنه تحديد الاحتياجات والاهتمامات الخاصة بالمعلومات والقدرة على تحديد مكانها وتقييمها وتنظيمها بكفاءة واستخدامها والاتصال بالمعلومات لمعالجة القضايا والمشاكل ، فهو جزء من حقوق الانسان للتعلم مدى ولات

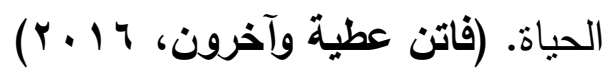

ويُعرف الوعي المعلوماتي إجرائياً في البحث الحالي بأنه امتلاك مجموعة

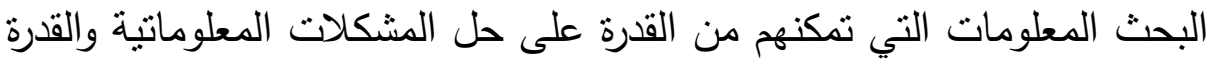

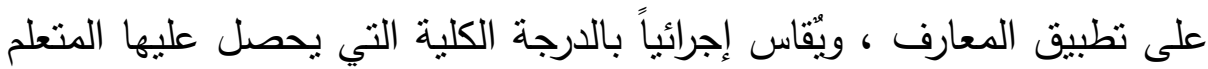

$$
\begin{aligned}
& \text { في إختبار الوعي المعلوماتي المطبق في البحث الحالي } \\
& \text { ثانياً - الواعي المعلوماتي: }
\end{aligned}
$$

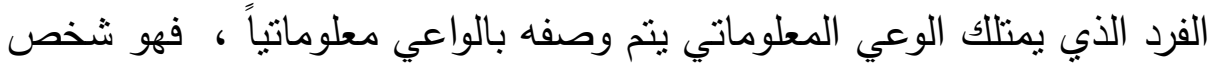
لايه مهارة حل المشكلات ومعرفة المعلومات ذات العلاقة ويمتلك مستوى عال

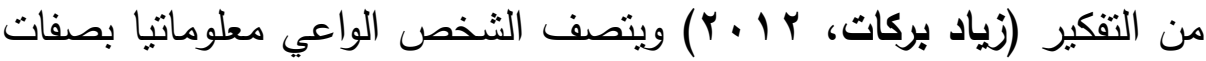
متعددة وصفتها و (قاطمة محمود ، 10 . ب) على النحو الآتي: هحدد طبيعة المعلومات التي يحتاجها ويصل إليها بكفاءة. يميز بين الرأي والحقيقة ، ويميز بين مصادر المعلومات الموثوقة والمصادر

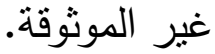


يعرف خطوات حل المشكلة المعلوماتية ويطبقها في البحث عن المعلومات. يقيم المعلومات ومصادرها ويربطها مع المعرفة السابقة لديه. يستخدم المعلومات ويشاركها مع الآخرين.

يفهر القضايا القانونية وحقوق الملكية واخلاقيات التعامل مع المعلومات واستخدامها.

يدرج أن المعلومات هي أساس القرار الصحيح في أب مجال. ثالثاً - مستويات الواعين معلوماتيا:

نظرا لاتساع مجال المعلومات واختلاف التخصصات العلمية واختلاف المستويات العقلية والمعرفية بين المتعلمين ، اهتمت العديد من الدراسات بتحديد

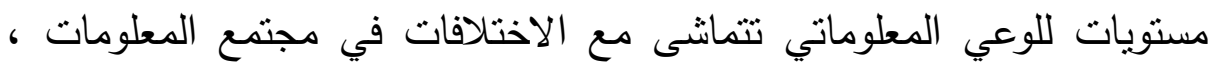
ففي دراسة لايفا سكولا (أيمن مصطفى، 10 ـ ب) نم تحديد ثلاث مستويات للوعي المعلوماتي وهي : مستوى الواعي المعلوماتي النمطي/التقليلي: يمتلك الواعي معلوماتيا فكرة عامة عن مفاهيم المعلومات ومصادرها وتقييمها واخلاقياتها ، مع امتلاك مهارات استخدام الادوات الاساسية في البحث الالكتروني عن المعلومات ومشاركتها.

مستوى الواعي المعلوماتي المتوسط: يمنلك الواعي معلوماتيا كافة مفاهيم المعلومات مع امتلالك القدر الكافي من مهارات التفكير الناقد والذي يمكنه من فلترة المعلومات وتدقيقها . مستوى الواعي المعلوماتي المنظور: يمتلك الواعي معلوماتيا معلومات متقدمة في مجال المعلومات وقوانين حماية الملكية الفكرية ، مع امتلاكى ملكي مستوى عال من مهارات التفكير الناقد ومهارات التعلم الذاتي ، وكذلك الاجادة التامة لمعظم ادوات البحث عن المعلومات ودمجها واعادة انتاجها. 
ونظراً لأهمية الوعي المعلوماتي اجريت العديد من الدراسات التي هدفت إلى التحقق من تشكيل الوعي المعلوماتي وتقييم الوضع المعلوماتي داخل مجتمعات أكاديمية منتوعة ومدى اكتساب أفراد تلأك المجتمعات للمفاهيم والمهارات المعلوماتية ومدى الصعوبات التي تواجه أفردها في مجال الوعي المعلوماتي وكيفية علاجها ، ومن تلاك الدراسات:

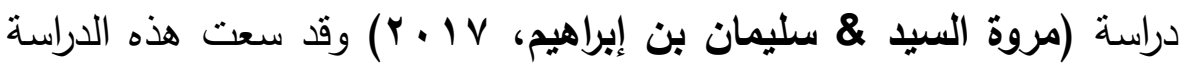
إلى تحليل واقع الوعي المعلوماتي لدى طالبات جامعة الجوف ، أظهرت النتائج اختلاف دافعية الطالبات في الحصول على المعلومات ، وأن مصادر المعلومات الإلكترونية هي التي يعتمد عليها بنسبة أكبر من المصادر الورقية ، وان اكثر الصعوبات التي تواجه الطالبات هي عدم احاطتهن بأماكن توفر مصادر المعلومات ، وأن اللغة الانجليزية كمصدر رئيسي للمراجع عاملا كبيرا في بوني صعوبة الحصول على المعلومات. ودراسة (إيمان جميل \& إبراهيم حربي، 17 ـ Y ) حيث هدفت إلى الكثف عن مستوى الوعي المعلوماتي لدى اعضاء هيئة التدريس بجامعة البلقاء ، وأظهرت النتائج وجود فروق ذات دلالة احصائية لصالح درجة استاذ ولصالح الكليات العملية ، وجاءت افضل المقترحات لتتمية اعضاء هيئة التدريس معلوماتيا هو تفعيل دور الجامعة في تتمية الوعي المعلوماتي لاعضائها من خلال عقد الورش واللقاءات الدورية والتدريبات.

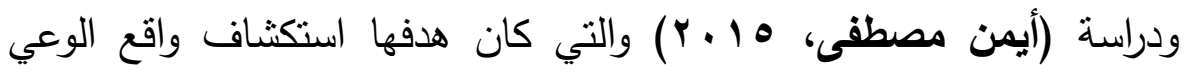
المعلوماتي لدى الباحثثن من طلاب الدراسات العليا بجامعة الدمام ، واظهرت النتائج مدى الحاجة لاكتساب مفاهيم الوعي المعلوماتي ولمهارات تقييم واستخدام المعلومات ، وأيضا اتضح افتقار غالبية الطلاب للمهارات التكنولوجية ، كما ماهي اتضح ان اكثر صعوبات التي تواجه المتعلمين تمحورت حول مصادر 
المعلومات وطرق استخدامها ، وذللك يقتضي ضرورة اعداد برنامج موحد للوعي المعلوماتي على اسس اكاديمية. ودراسة (Lin, 2014) والتي هدفت إلى مقارنة بين طلاب التخصص العلمي وبين طلاب التخصص الادبي في الوعي المعلوماتي ، وقد اسفرت نتائج الدراسة عن وجود فروق دالة احصائيا لصالح طلاب التخصص العلمي في جمع المعلومات ومهارات الوعي المعلوماتي ، ويرجع السبب إلى تفوق طلاب التخصص العلمي في استخدام مهارات التفكير الناقد والذي تم تتميته لديهم من خلال مقرراتهم العلمية التي تشجع على انتقاء المعلومات والبحث. ودراسة (علي الحر، \& 1 ـ ب) والتي كان هدفها قياس الوعي المعلوماتي لاى الطلاب بجامعة المستتصرية ، توصلت النتائج إلى تفوق طلاب التخصصات العلمية في مستوى الوعي المعلوماتي عن طلاب الكليات ذات التخصصات الانسانية. يتبين من عرض الدراسات السابقة ما يلي: لا يمنالك العدد الكافي من المتمعات الأكاديمية الوعي المعلوماتي بشكل متكامل ، حيث يوجد خلط في بعض مفاهيم الوعي المعلوماتي ، ويوجد قصور واضح في امتلاك المتعلمين لمهارات البحث وتفنيد وتوثيق المعلومات ، كما أن المعلومات القانونية الخاصة بحقوق الملكية الفكرية ليست معروفة إلا لأعداد أقل من المتوسط. توجد فروق بين المتعلمين في الوعي المعلوماتي يرجع لاختلاف التخصصات العلمية ، وقد يرجع هذا إلى طبيعة المقررات الدراسية التي تتعامل مع مجال المعلومات لدى بعض التخصصات وإهمالها لدى الآخر . توجد صعوبات في الحصول على المعلومات من مصادر موثوقة لدى قطاع كبير من المتعلمين برجع إلى عوائق اللغة ومهارات البحث الاككتروني ومهارات استخدام قواعد البيانات العالمية. 
توجد علاقة ايجابية بين امتلاك المتعلمين لمهارات معينة منل التفكير الناقد

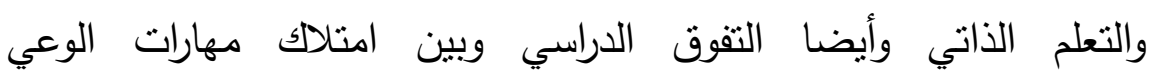
المعلوماتي. رابعاً- الاهمية التريوية للوعي المعلوماتي: للوعي المعلوماتي أهمية كبيرة في مجالات الحياة المختلفة ومن ضمنها

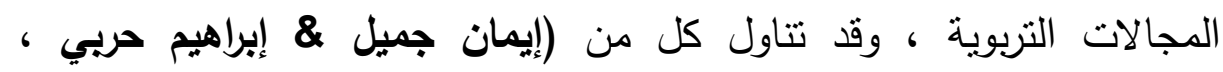

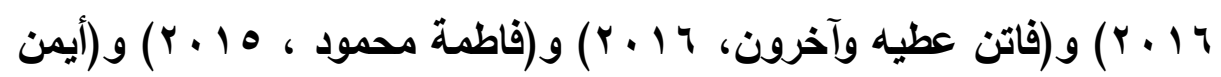

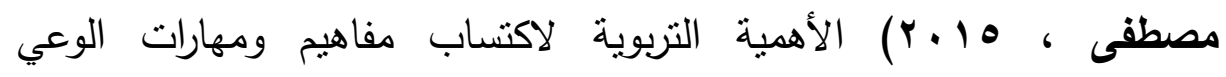
المعلوماتي على النحو التالي: تطوير لمهارات التعلم الذاتي والتعلم المستمر من خلال القدرة على البحث وتقييم المعلومات واعادة انتاجها. مشاركة المعلومات مع الأقران وبالتالي زيادة فاعلية التعلم من خلال تطبيق استراتيجيات تعليمية نشطة مثل التعلم التعاوني والتعلم التشاركي. تمكين المتعلمين من حل مشكلاتهم المعلوماتية من خلال اتباع استراتيجيات سليمة في البحث والثقييم. التعامل مع التغييرات السريعة في المعلومات من خلال التمبيز الانسب والاصح بين المصادر المنتوعة. زيادة المهارات الثخصية للمتعلم وبالتالي زيادة فرصه في الحصول على

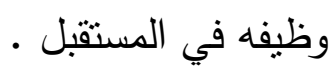
الاستخدام الاخلاقي للمعلومات ومراعاة حقوق الملكية الفكرية تعد من المهارات البحثية الأساسية واكتسابها يسهم في تطوير المجتمع الأكاديمي بشكل عام. 
الأهمية التربوية للوعي المعلوماتي دفعت الباحثنن لاجراء دراسات حول الطرق المختلفة لاكساب المتعلمين مفاهيم ومهارات الوعي المعلوماتي ومن تلك الدراسات:

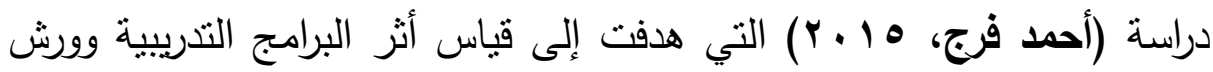
العمل على تطوير سلوكيات وكفاءة اجراء البحث المعلوماتي ، أثنارت النتائج إلى أن تتفيذ البرامج التدربيية إدى إلى تسهيل عرض مهارات البحث المعلوماتي مما أدى إلى سهولة تطبيقها وتتمية سلوكيات معلوماتية ايجابية لدى المتدربين. ودراسة (محمود جابر، 10 • ب) والتي هدفت إلى التحقق من فاعلية استخدام نموذج حل المشكلة المعلوماتية في تتمية الوعي المعلوماتي والمهارات

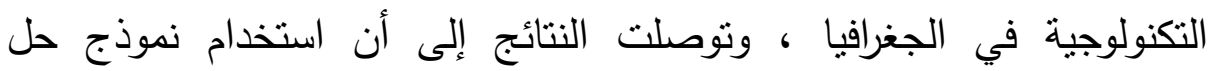

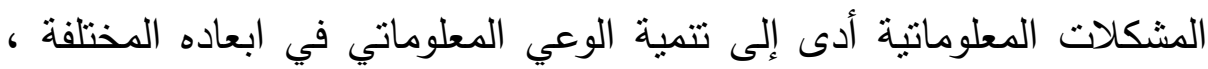
وبرجع ذللك إلى ان النموذج المقترح مكن المتعلمين من ممارسة عملية البحث

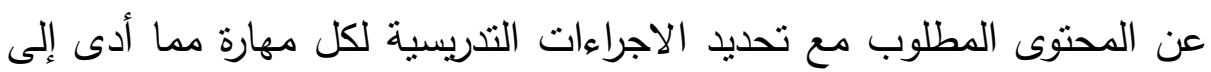

تعلمها

ودراسة (فاطمة محمود، 10 ب r) حيث هدفت إلى قياس فاعلية برنامج تدريبي قائم على مهارات التفكير الناقد التمبيزية لتتمية الوعي المعلوماتي لدى طلاب الدراسات العليا ، توصلت النتائج إلى وجود فاعلية للبرنامج التعليمي في تتمية الوعي المعلوماني ، ويرجع السبب إلى أن ممارسة التفكير الناقد بمهارات التمبيزية نساعد في حل المشكلات المعلوماتية النابعة من مصادر المعلومات الإلكترونية وتساعد في فلترة الحقائق والاراء المتعددة التي تتطلب التمبيز

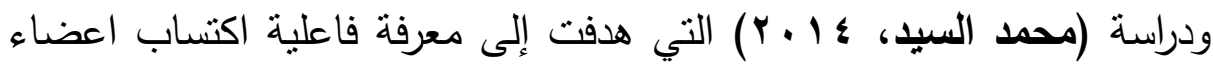
هيئة التدريس لمهارات استخدام نظام ادارة التعلم في تتمية الوعي المعلوماتي لايهم ، وتوصلت إلى وجود فاعلية التدريب على استخدام نظام ادارة التعلم في تتمية الوعي المعلوماتي لدى مجموعة البحث ، وبرجع السبب إلى شمول نظام 
ادارة التعلم لمفاهيم الوعي المعلوماتي والارتباط الواضح بين مهارات استخدام النظام وبين مهارات البحث عن المعلومات والاستفادة منها ، حيث ان امتلاك مهارات استخدام نظام الادارة يؤدي في الغالب لامتلاك مهارات الوعي المعلوماتي يتبين من عرض الدراسات السابقة ما يلي: تتوعت الطرق المستخدمة في تتمية الوعي المعلوماتي مابين طرق إلكترونية وأخرى تقليدية وأخرى مدمجة بين الإلكترونية والتقليدية. العائق الرئيسي في تطبيق مهارات الوعي المعلوماتي هو عدم ادراك المتعلمين لها من الأساس ، وتدريبهم عليها يسهل تطبيق تلك المهارات. مهارات التفكير الناقد والتعلم الذاتي وحل المشكلات ترتبط ارتباط كبير

$$
\text { بالوعي المعلوماتي. }
$$

اكتساب المهارات التكنولوجية لنظم ادارة المحتوى ينمي بشكل مباشر

$$
\text { مهارات الوعي المعلوماتي. }
$$

يوجد ارتباط بين تتمية مفاهيم ومهارات الوعي المعلوماتي وبين تتمية الاتجاهات الايجابية حول مجتمع المعلومات وما يشمله من مفاهيم

$$
\text { ومهارات. }
$$

وقد هدفت العديد من الدراسات تقييم المناهج الدراسية والوقوف على مدى توفر مفاهيم ومهارات الوعي المعلوماتي ومن تلك الدراسات:

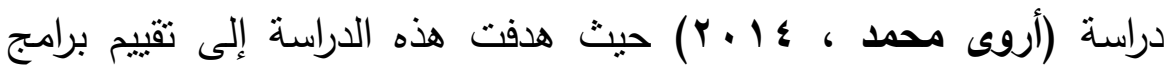
الوعي المعلوماتي التي تقدمها المكتبة المركزية لجامعة الملك عبداله ، وتوصلت الدراسة إلى عدة نتائج أهمها عدم وجود برنامج منكامل للوعي المعلوماتي وضعف الاقبال على البرامج الأخرى التي تقدمها المكتبة.

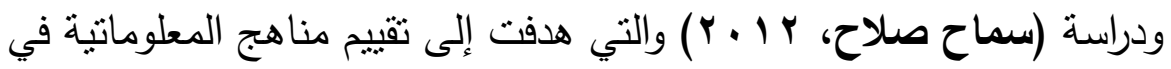
مصر في مقررات المكتبات ومقررات الحاسب الآلي ، وكانت من أهم نتائج تلك 
الدراسة عدم وجود مناهج فعالة لتعليم المهارات المعلوماتية في مراحل التعليم ما قبل الجامعي ، مع افتقاد المناهج الدراسية الاخرى عناصر تشجيع الطلاب على البحث عن المعلومات. وهذا ما أدى بالباحثين إلى اجراء دراسات حول اعداد معايير مقننة للوعي المعلوماتي يتم دمجها في تلاك المقررات ومن تلك الدراسات: دراسة (فاتن عطية وآخرون، 17 + ب) والتي هدفت إلى تصميم برنامج قائم على النظرية البنائية التفاعلية لتتمية مهارات الوعي المعلوماتي ، وقد توصلت الدراسة إلى بناء قائمة بمعايير الوعي المعلوماتي المناسبة وتحديد المؤشرات المطلوبة لكل معيار ، وكذلك تقديم برنامج مقترح قائم على النظرية البنائية

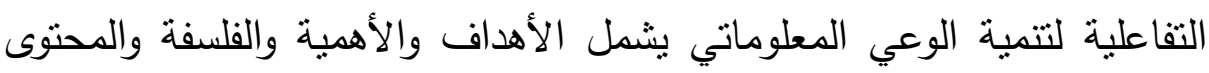
التعليمي واستراتيجيات التتريس ومصادر التعلم ووسائل التقويم.

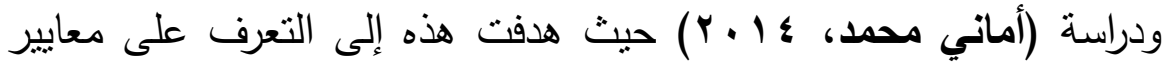
الوعي المعلوماتي المطبقة في بعض الجامعات العالمية ، وكذلك تقييم معايير الوعي المعلوماتي في مصر ، وقد توصلت الدراسة إلى معايير إقليمية نابعة من المعايير المطبقة في الجامعات والمعاهد الأمريكية ويصلح تطبيقها في المؤسسات الأكاديمية المصرية.

سادساً - الأسس التريوية والنفسية التي يقوم عليها الوعي المعلوماتي: خلا مراجعة الدراسات السابقة في هذا المحور وبالاطلاع على العديد من

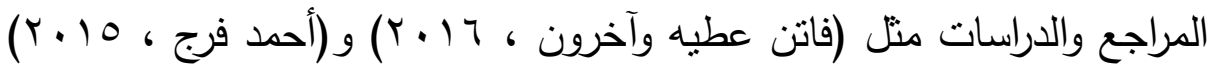

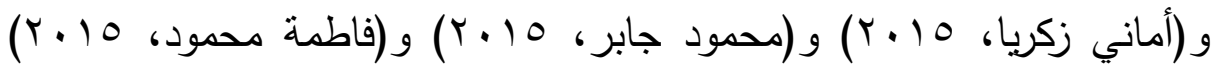
توصل الباحث إلى الأسس التربوية والنفسية التي يقوم عليها الوعي المعلوماتي وهي كما يلي: 
• حل المشكلات : تتداخل مهارات الوعي المعلوماتي مع مهارات حل المشكلات في التعرف على المشكلة المعلوماتية والتعبير عنها من خلال كلمات بحثية دالة ، وتحديد مصادر المعلومات المطلوبة لحل المشكلة ، وأخيرا الوصول للمعلومات وتقييمها التفكير الناق : يقوم الوعي المعلوماتي على أسس من التفكير الناقد من خلال التقييم النقدي لمعلومات عن طريق الفحص الدقيق للمعلومات المعروضه بهدف تحديد مواطن القوة والضعف، وفهم البنى التحتية التي تعد

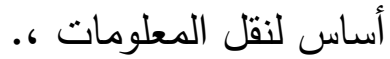
اتخاذ القرار : يعتمد الوعي المعلوماتي على تحديد انواع المعلومات اللازمة لحل المشكلة من خلا التفكير في أنواع المعلومات المطلوبة وكميتها وأثكالها ثم استخدام تلك المعلومات في اتخاذ القرارات. التعلم الأتي : مرحلة النضج المعلوماتي للمتعلم ترتبط بممارسة التعلم الذاتي حيث يعتمد الطالب على نفسه في التحصيل وأن يبحث عن التميز في مجال البحث عن المعلومات والحصول على المعرفة ، فالتعلم الذاتي يعتمد على قدرة الطالب على معرفة كيف يتعلم ويقوم بدور فعال في كسب المعلومات معتمدا على ذاته .

\section{المحور الثالث - السعة العقلية: \\ أولاًَ- مفهوم السعة العقلية:}

عرف (جان باسكال- ليون) السعة العقلية بأنها جزء محدود من الذاكرة يتت فيها معالجة كل المعلومات المستقبلة والمسترجعة في وقت واحد ، وبالتالي فهي تمنل العدد الأقصى من المخططات التي يسنطيع العقل تجميعها في فعل عقلي

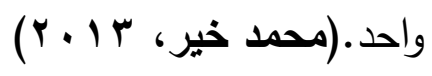


وعرفها (اسعاد البنا \& حمدي البنا ، .99 199) بأنها أقصى عدد من وحدات المعلومات التي يستطيع الفرد التعامل معها في آن واحد ، فهنالك من يستطيع

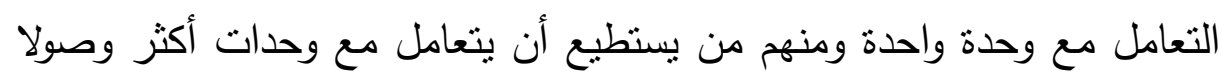

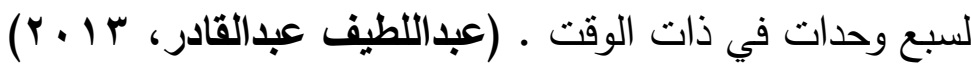
وقد تبنى البحث الحالي تعريف (جان باسكال - ليون). ثانياً - خصائص السعة العقلية: أوضحت (Edwards, 2017) الخصائص التي تمثل الحد الادنى من السعة العقلية والتي تتوفر للمتعلمين من غير ذوي الفئات الخاصـة ، وهي على النحو التالي: امتلاك الحد المتوسط من فهم المعلومات التي تدور حولهم. الاحتفاظ بالمعلومات لوقت كافي وطبيعي. امتلاك القدرة العقلية على اتخاذ القرار بشكل عام. التعبير عن الاسباب التي تجعلهم يتخذون قراراً محدداً. لا يسمحون بإكراهه على اتخاذ القرارات دون ارادتهم إلا في وجود اسباب واضحة.

ثالثاً - الأهمية للسعة العقلية في التعليم: إنهاب

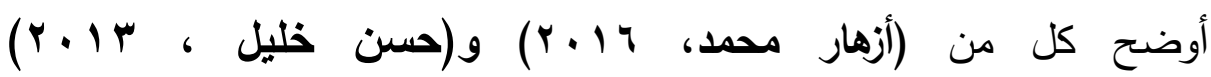
و(عبداللطيف عبدالقادر، ب ا ـ r) الأهمية التربوية للسعة العقلية واختلاف مستوياتها بين المتعلمين على النحو الآتي: • أحد محددات عملية التفكير والتعلم والمسئولة عن المفاهيم المعرفية والمثيرات التي تؤدي دوراً مهماً في الأنشطة الحياتية والتعليمية. الطلاب المنخفضين في السعة العقلية لديهم صعوبات تعليمية خصوصا في مجالات الرياضيات. 
لا يتساوى الطلاب في قدراتهم ولا في طريقة تعلمهم وبالتالي لابد من مراعاة اختلاف مستويات السعة العقلية في مراحل تصميم وتتفيذ المواقف التعليمية. توجد علاقة ارتباطية موجبة بين السعة العقلية والتحصيل الدراسي. وقد قامت عديد من الدراسات بقياس مستويات السعة العقلية لدى المتعلمين وقارنت بين أثز اختلاف تلك المستويات على تحقيق الأهداف التعليمية المختلفة ومن تلاك الدراسات: دراسة (أزهار محمد، 17 ـ ب) والتي هدفت إلى معرفة مستوى السعة العقلية للى طلاب الجامعة بحسب متغيرات الجنس والتخصص الدراسي ، أظهرت النتائج ان طلاب الجامعة سعتهم العقلية منوسطة بصورة عامة ، وانه لاتوجد فروق في السعة العقلية بين الأكور والاناث ، ولكن طلاب الكليات العملية سعتهم العقلية أوسع مع الكليات الانسانية. ودراسة (عبدالله عصام، ؟ 1 • ب) التي هدفت إلى معرفة علاقة السعة العقلية بمفهوم الذات واتخاذ القرار لدى تلاميذ المرحلة الاعدادية ، وتوصلت النتائج إلى وجود علاقة ارتباطية موجبة بين السعة العقلية وبين مفهوم الذات واتخاذ القرار ، كما توصلت الدراسة أيضا إلى أن التلاميذ يتمتعون بمستوى جيد من السعة إنه العقلية لصالح الإناث.

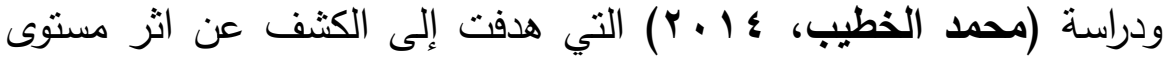
السعة العقلية في القدرة على حل المشكلات الرياضية لتلاميذ المرحلة المتوسطة ، وأظهرت النتائج أن التلاميذ ذوي السعة العقلية المرتفعة لديهم القدرة على حل المشكلات الرياضية المصاغة بقالب رمزي وبقالب رمزي أفضل من التلاميذ

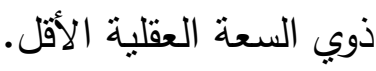
ودراسة (عبداللطيف عبدالقادر، بr ب r) التي هدفت إلى إعداد برنامج لتدريس الادب العربي في المرحلة الثانوية في ضوء مستويات السعة العقلية ، ونوصلت نتائج الدراسة إلى تفوق المجموعة التجريبية التي تدرس باستخدام برنامج يراعي 
اختلاف مستويات السعة العقلية عن المجموعة الضابطة التي تدرس بطريقة تقليدية

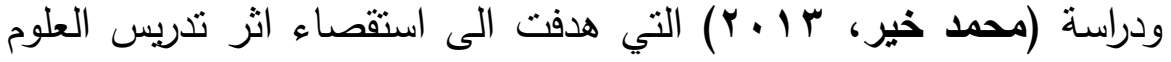

بطريقة الانشطة العلمية في تحصيل الطلاب ذوي السعات العقلية المختلفة في تتمية المفاهيم والاتجاهات العلمية ، وقد أظهرت النتائج وجود فروق دالة احصائيا لصالح الطلاب ذوي السعة العقلية الأعلى ، يرجع السبب في ذلك إلى وجود علاقة بين السعة العقلية والتحصيل حيث أن السعة العقلية نقل كفاءتها بسبب الحمل الزائد في المعلومات. يتبين من عرض الدراسات السابقة ما يلي: يوجد تفاوت في السعة العقلية بين المتعلمين في أي مجتمع دراسي ، إلا أن المستوى المتوسط هو الاكثر انتشارا.

لاتوجد فروق في السعة العقلية بين الذكور والاناث في المراحل الجامعية ، ولكن ظهرت فروق بين الجنسين في مراحل المدرسة في بعض الدراسات. التلاميذ ذوي السعة العقلية الأعلى أكثر تفوقا في الدراسة وأكثر قدرة على حل المسائل الرياضية وأكثر قدرة على التحصيل . يمكن لطريقة التدريس المناسبة أن تراعي التتوع في مستويات السعة العقلية عن طريق تقلل الحمل الزائد للمعلومات وبالتالي يمكن لمنخفضي لئي السعة العقلية مجاراة مرتفعي السعة العقلية في التفوق الدراسي. طلاب التخصصات العلمية سعتهم العقلية أكبر من طلاب التخصصات الانسانية ، وقد يرجع ذللك إلى أن الكليات العملية تشنرط مجموع دراسي أكبر للالتحاق بها وبالتالي يلتحق بها المتفوقون دراسيا والذي يكونون بالتالي أكثر قدرة من حيث السعة العقلية. 


\section{تمثلت الاستفادة من الاطار النظري للبحث في :}

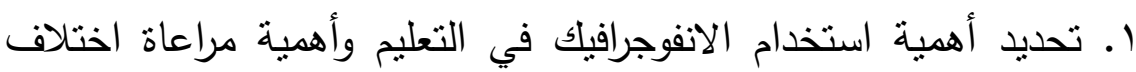
مستويات السعة العقلية بين المتعلمين وأهمية اكساب الوعي المعلوماتي الهي r. تحديد أنواع وأنكال ومعايير تصميم الإنفوجرافيك الثابت والمتحرك r. تحديد معايير أنتاج الانفوجرافيك الثابت والانفوجرافيك املتحرك ع. وضع ارشادات للباحث ليقوم بتصميم وإنتاج مادتي المعالجة التجريبية

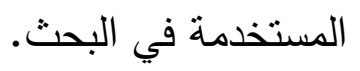

0. تحديد مفاهيم الوعي المعلوماتي المطلوب اكسابها لطلاب الجامعة T. التوصل إلى ادوات القياس المستخدمة في البحث وهي إختبار السعة

$$
\text { العقلية وإختبار الوعي المعلوماتي . }
$$

V. في تفسير نتائج البحث الحالي وكتابة التوصيات البحثية.

$$
\text { أولاء- منهج البحث: البحث: }
$$

استخدم البحث الحالي المنهج شبه التجريبي لتعرُف أثز المتغير المستقل الإنفوجرافيك (ثابت- متحرك) على متغير تابع مستوى مجموعة البحث في إختبار الوعي المعلوماتي في ضوء متغير تصنيفي وهو مستويات مختلفة من السعة العقلية وذلك في مرحلة التقويم النهائي.

$$
\text { ثانيا- متغيرات البحث: }
$$

1-المتغير المستقل: نمطين من الإنفوجرافيك (ثابت - متحرك). r-المتغير التصنيفي : مستوبات مختلفة من السعة العقلية. r-المتغير التابع: الوعي المعلوماتي. 


\section{ثالثا - التصميم التجريبي للبحث :}

استخدم البحث الحالي التصميم التجريبي العاملي (Y×r) لقياس تأثير المتغير المستقل الإنفوجرافيك بنوعيه (الثابت والمتحرك) والمتغير التصنيفي السعة العقلية بمستوياتها (مرتفع ، منتوسط ، منخفض) ، وذلك على المتغير التابع مستوى

$$
\text { الوعي المعلوماتي. }
$$

طلاب الفرقة الثالثة كلية التربية جامعة المنيا ، لي العام الأكاديمي

$$
\begin{aligned}
& . r \cdot 1 V / r .17 \\
& \text { خامسا- عينة البحث : }
\end{aligned}
$$

تم اختيار عينة من طلاب الفرقة الثالثة بكلية التربية وبلغ عددهم ( • ( ) طالب

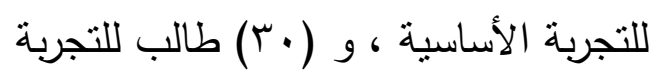
سادسا - إعداد أدوات القياس :

تمنلت أدوات القياس في البحث الحالي في إختبار الوعي المعلوماتي وإختبار السعة العقلية ، ومر ضبط الإختباران بالمراحل التالية:

$$
\text { ا - إختبار الوعي المعلوماتي: }
$$

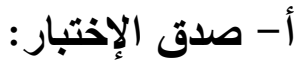

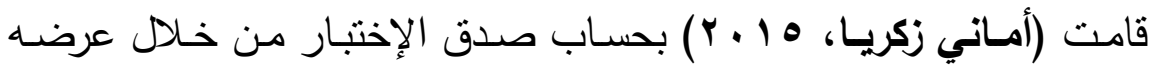
على مختصـين لتحكيمسه مـن تخصصـات علم النفس التربوي وتخصـص الوثائق والمعلومات واتضح انه يقيس بالفعل ما وضع لقياسه.

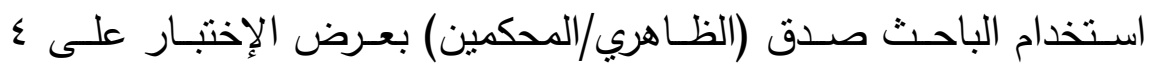

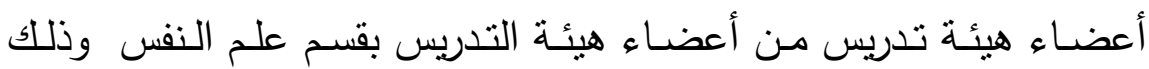

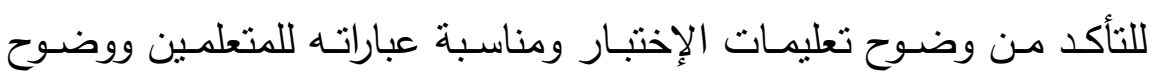


الأهداف ، وأظهرت نتائج التحكيم صدق الإختبار وأنه صالح للتطبيق على المتعلمين بنسبة موافقة و \% \%

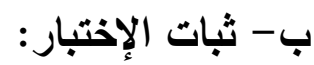

اعتمدت (أماني زكريا، 10 ـ ب) في ثبات الإختبار على العوامل الآتية: طـول الإختبـار : حيث أن هنـالك تتاسـب طـردي بـين طـول الإختبـار ودرجة ثباته.

توسط صسعوبة مفردات الإختبار : حيث أن الاسئلة شديدة الصـوبة والاخرى شديدة السهولة تقلل من ثبات الإختبار .

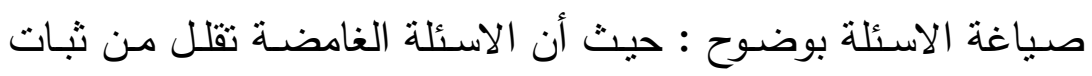

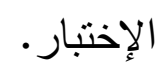

قـام الباحـث بحسـاب ثبـات إختبـار الـوعي المعلومـاتي باسـتخدام طريقـة

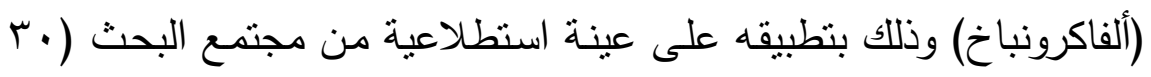
طالب) ومن غير العينة الاصلية ، واتضح أن معامل ثبات (الفاكرونباخ) للإختبار يساوي ( ع V. . ) مما يشير إلى تمتعه بدرجة مقبولة من الثبات. r - إختبار السعة العقلية: أ- صدق الإختبار : قام باسكال ليون باستخراج صدق البناء للإختبار انطلاقا

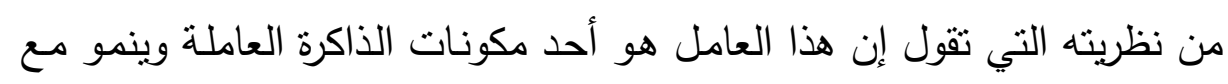
العمر وقد حسبت نسب ، وقد قـام كل مـن اسـعاد البنـا وحمدي البنـا بترجمـة هونة

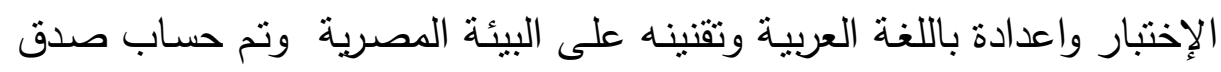

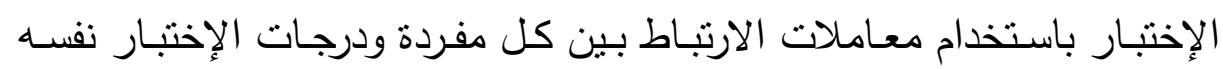

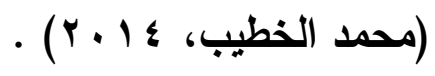
• استخدام الباحث صدق (الظاهري/المحكمين) بعرض الإختبار على مجموعة

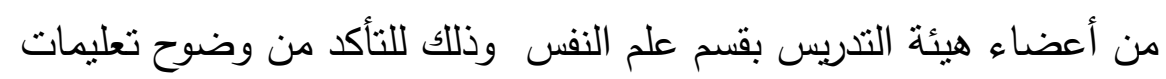
الإختبـار ومناسبة عباراتـه للمتعلمين ووضـوح الأهداف ، وأظهـرت نتهائج 
التحكيم صدق الإختبار وأنـه صـالح للتطبيق على المتعلمين بنسبة موافقة

$$
. \% 1 \text {. . }
$$

ب- ثبات الإختبار:قام كل من اسعاد البنا وحمدي البنا ـ 199 بحساب صدق الإختبار باستخدام التجزئة النصفية وتراوحت معاملات الثبات مابين (Tی. · و

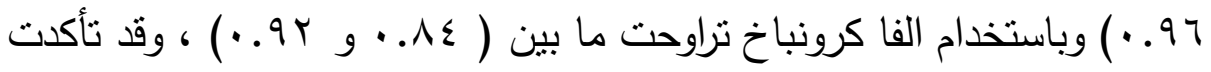

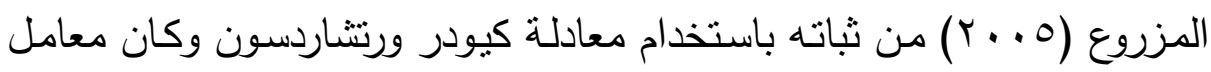

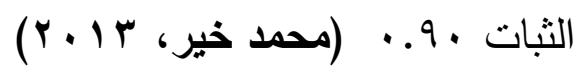

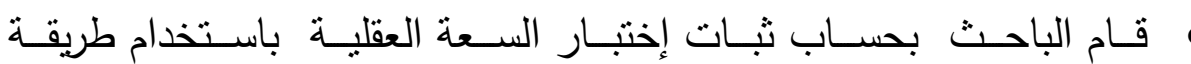

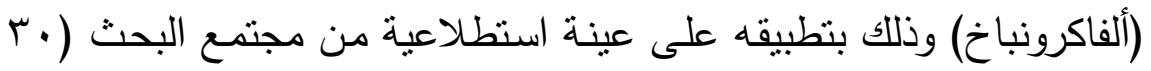
طالب) ومن غير العينة الاصلية ، واتضح أن معامل ثبات (الفاكرونباخ) للإختبار يساوي (11. . ) مما يثنير إلى تمتعه بدرجة جيدة جدا من الثبات. سابعا - بناء مادتي المعالجة التجريبية :

ADDIE اعتمد الباحث في تصميم مادتي المعالجة التجريبية على نموذج المرجعي الذي يتكون من خمس مراحل وهي : التحليل والتصميم والتطوير والتتفيذ والتقويم ، وتم بناء المعالجتان التجريبيتان وفق المراحل الآتية:

\section{1- مرحلة التحليل :}

• تحـيـ خصـائص المتعلمـين : تقارُب خصـائص النمو الجسدية والانفعاليـة والاجتماعية حيث أنهم ينتمون لمرحلة الثباب فهي المرحلة الانتقالية بين تبعية الطفولة وتحمل حقوق وواجبات البالغين فهي مرحلة التجريب لأدوار ومهام جديدة. تحديد الاحتياجات التعليمية: تحددت الاحتياجات التدريبية لدى طلاب كلية التربية النوعية في تتمية الوعي المعلوماتي وأبعادها هي القدرة على تذكر معلومـات ومفـاهيم، القدرة على حلى المشـكلات المعلوماتيـة، القدرة على 
تطبيق المعارف وذلك وفق إختبـار الوعي المعلومـاتي الذي تم تبنيـه في

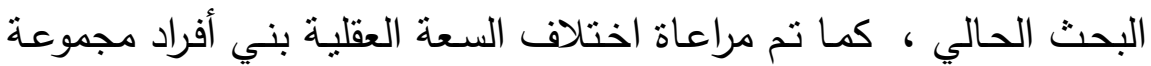
البحث من خلال التتوع في نمط الإنفوجرافيك المقدم (ثابت - متحرك)

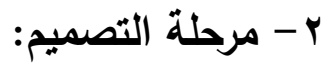

صياغة الأهداف العامة :في ضوء إختبار الوعي المعلوماتي المستخدم في هرجي البحث الحالي تمثل الهدف العام في تمثل في اكساب طلاب كلية التربية النوعية الوعي المعلوماتي ، وتمثلت الاهداف الفرعية فيما يلي: O اكساب المفاهيم الاساسية الخاصة بالوعي المعلوماتي. o اكساب المفاهيم الاساسية الخاصة بالبحث عن المعلومات. م اكساب المفاهيم الاساسية الخاصة بحقوق الملكية الفكرية واخلاقيات

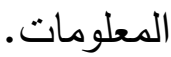
تحليل المحتوى التعليمي: مر إعداد المحتوى وتتظيمه بالخطوات التالية : O هدفت عملية تحليل المحتوى إلى بناء محتوى يتضمن من مفاهيم ومبـادئ وإجـراءات وحقـائق ليقوم بإكسـاب طـلاب كليـة التربيـة النوعية مفاهيم الوعي المعلوماتي.

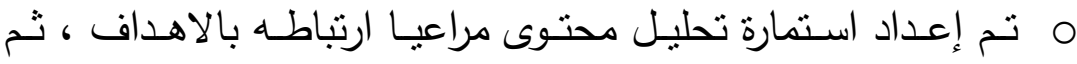
بحساب ثبات تحليل المحتوى بالتحليل الكمي والكيفي مرتين بفاصل ع أسـابيع ، وتم بالابقاء على الموضوعات المشتركة بين التحليلين

$$
\text { والتي بلغت } 19 \text { موضوع }
$$

م تم اعداد المحتوى في شكله النهائي في صورة ب وحدات تعليميـة بحيث تهدف كل وحدة إلى اكساب مفاهيم تخص أحد مجـالات

$$
\text { الوعي المعلوماتي }
$$


O ت تم اعداد قائمة بالاهداف المعرفية مصاغة في شكل عبارات سلوكية بحيـث تصـف سـلوك المـتعلم ويكـون هـذا السـلوك قـابلا للقيـاس

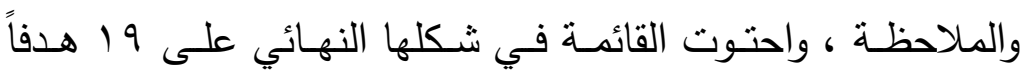

$$
\text { تعليمياً كما يوضحها الجدول الآتي: }
$$

جدول (ع) الاهداف التعليمية لمحتوى الوعي المعلوماتي وفق تصنيف بلوم

\begin{tabular}{|c|c|c|c|c|c|c|c|}
\hline \multirow{2}{*}{ مجموع } & \multicolumn{6}{|c|}{ عدد الاهداف } & \multirow{2}{*}{ الوحدة التعليمية } \\
\hline & تقويم & تركيب & تحليل & تطبيق & فهم & تذكر & \\
\hline 7 & - & - & r & - & r & 1 & الوعي المعلوماتي \\
\hline$\wedge$ & 1 & 1 & - & 1 & $\varepsilon$ & 1 & البحث عن المعلومات \\
\hline 0 & - & 1 & 1 & - & r & 1 & حقوق الملكية الفكرية \\
\hline $\begin{array}{l}19 \\
\text { هدفاً } \\
\text { تعليمياً }\end{array}$ & 1 & r & r & 1 & 9 & r & المجموع \\
\hline
\end{tabular}

للاستخدام داخل الإنفوجرافيك بالخطوات الآتية:

أ- - صياغة المحتوى العلمي بحيث بسهل تصميمه بصريا باستخدام الإنفوجرافيك (اختصار المحتوى - تحديد الرسومات المناسبة التي

$$
\text { تعوض عن حذف المعلومات الزائدة) }
$$

ب-تقسيم المحتوى الواحد إلى إجزاء صغيرة بحيث يكون كل جزء من هذه الاجزاء صالحا للامج داخل إنفوجرافيك مصغر لهراء ، ليتم تجميع هذه

الاجزاء في شكل إنفوجرافيك اكبر • 
تعديد استراتيجية التعلم : استخدم الباحث نمط التعلم الذاتي الذي يتم دون مساعدة من المعلم ويقوم المتعلم بنفسه بالسعي لتحقيق أهداف التعلم من البن

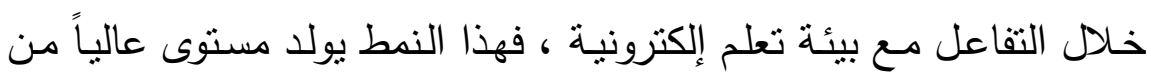

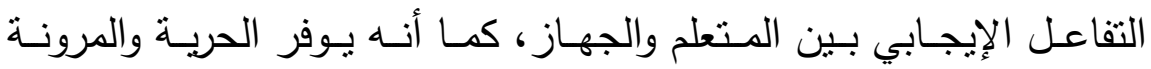
لاستكثاف المفاهيم والحقائق عن طريق أنماط المواد التعليمية

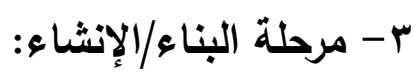

\section{الإعداد الأولي المواد والوسائط التعليمية :}

تم انتاج الإنفوجرافيك عن طريق انتاج العناصر الفرعية الآتية: أ- العنصـر البصـري الذي تضـن الألموان والرسومات كالأسهم والأشكال التلقائية وغيرها ، وقد تم استخدام الخطوط والألوان والأشكال المناسبة

$$
\text { التي تجمع بين البساطة والوضوح والإبداع الفني. }
$$

ب- المحتوى النصـي : الـذي شـمل النصـوص المكتوبـة بشـكل مختصـر ومتربط بالعنصر البصري.

ج- التنظيم :تم التتوع في طرق تنظيم العناصر البصرية والمحتوى النصي

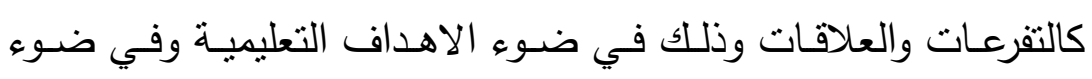

$$
\text { المحتوى }
$$

بـرامج الكمبيـوتر المسـتخدمة : تـم اسـتخدام بـرامج كمبيـوتر في إنثــاء Adope - Adope Photoshop) الإنفوجرافيك ، حيث تم استخدام Adope after) في تصميم الإنفوجرافيك الثابت وتم استخدام (Illustrator (effects

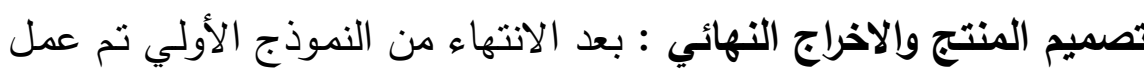

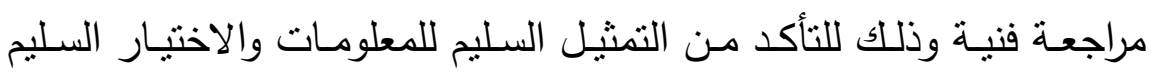
للرسومات وسلامة اللغة. 
الفروق الانتاجيـة بين الإنفوجرافيك الثابت والمتحرك : في الإنفوجرافيك المتحرك تم مراعاة وضوح الصوت ونقاؤه ومزامنة الصوت مـع الحركة وتم الصن

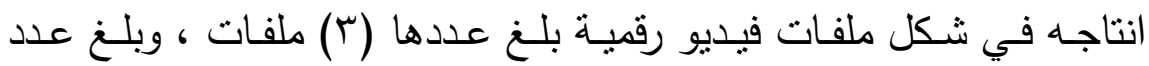
ملفات الإنفوجرافيك الثابت (r) صور رقمية

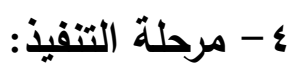

تجهيز البيئة التعليمية: تم تجهيز ملفات الإنفوجرافيك للاستخدام بتحميلها على بيئة تعلم إلكترونية ، وتم عمل account لكل فرد من افراد العينة يتيح

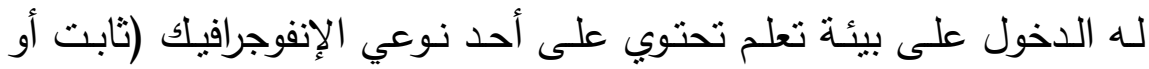
متحرك).

التـدريب على اسـتخدام بيــة التعلم: تم تتفيذ جلسـة إرشـادية تم لتوضيح الهدف مـن التطبيـق العملي لتجربـة البحث ومفهوم الإنفوجرافيك والـوعي

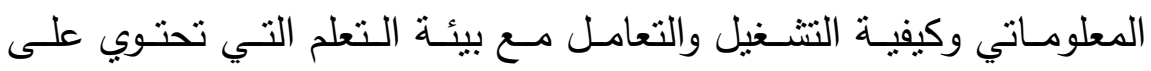
الإنفوجرافيك. 0- مرحلة التقويم: تم تطبيق مادة المعالجة التجريبية على عينة استطلاعية من مجتمع البحث (،0 طالباً وطالبة) ومن غير العينة الاصلية ، للتأكد من سهولة مادة استخدامها ، ومناسبتها لمجموعة البحث ، والجودة الفنية والتقنية .

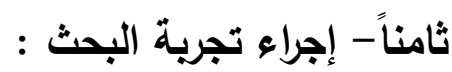
مر إجراء تجرية البحث بالخطوات التالية: 1- اختيار عينة البحث :تم اختيار مجموعات البحث (الاستطلاعية والتجريبية والضابطة) بطريقة عشوائية. حيث بلغ عدد مجموعة البحث الاستطلاعية ( (0)

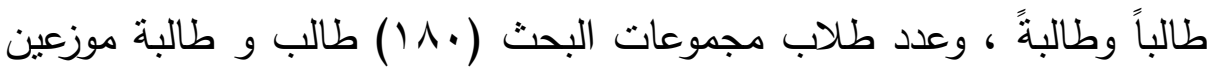
على 7 مجموعات فرعية. r- التجربة الاستطلاعية:استهدفت هذه الخطوة توثيق أدوات القياس ، وكذلك فحص مادة المعالجة التجريبية ، وذللك عن طريق تطبيقهم على عينة 
استطلاعية من مجتمع البحث (·r طالب) ومن غير العينة الأصلية ، وتم عمل التوثيق اللازم لأدوات القياس وعمل التعديلات المطلوبة على مادة المعالجة التجريبية.

ع- التمهيد للتجربية : قام الباحث بتتفيذ ورشة عمل تعريفية بالتطبيق تم فيها توضيح الهدف العام للبرنامج، شرح الأهداف العامة الفرعية ، شرح كيفية التعامل مع بيئة التعلم الإلكترونية ، توزيع الجدول الزمني للتدريب. 7- تصنيف مجموعات البحث:هدفت هذه الخطوة إلى تصنيف مجموعة البحث ، حيث تم تصنيفهم في البداية وفقا لمستويات السعة العقلية لديهم حسب أداؤهم في إختبار السعة العقلية لباسكال ليون كما يوضح الجدول الآتي:

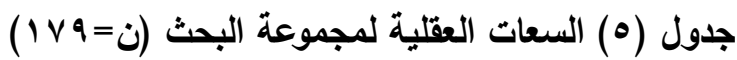

\begin{tabular}{|c|c|c|}
\hline النسبة المئوية & عدد الطلاب & مستوى السعة العقلية (س) \\
\hline$\%$ \%r & $0 \wedge$ & W = \\
\hline$\% r v$ & 77 & س = \\
\hline$\%$ & 07 & س = \\
\hline
\end{tabular}

ثم تم التقسيم العشوائي لطلاب المستوى الواحد من السعة العقلية إلى مجموعتين الأولى تدرس باستخدام الإنفوجرافيك الثابت والأخرى تدرس بالإنفوجرافيك المتحرك ، ويوضتح الجدول التالي نتائج تتصيف مجموعات البحث: 


\begin{tabular}{|c|c|c|c|}
\hline مادة المعالجة & مستوى السعة & عدد أفراد & رقم \\
\hline إنفوجرافيك ثابت & W = & rq & 1 \\
\hline إنفوجرافيك متحرك & س = & rq & r \\
\hline إنفوجرافيك ثابت & س = & 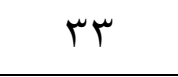 & 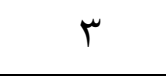 \\
\hline إنفوجرافيك متحرك & س = & 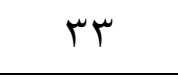 & $\varepsilon$ \\
\hline إنفوجرافيلك ثابت & س = & rᄉ & 0 \\
\hline إنفوجرافيك متحرك & س = & rᄉ & 7 \\
\hline
\end{tabular}

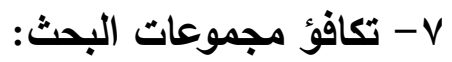

هدف التطبيق القبلي لإختبار الوعي المعلوماتي إلى التأكد من عدم وجود فروق بين جيع مجموعات البحث من خلال إختبار تحليل التباين في اتجاه واحد One Way ANOVA لحساب الفرق بين متوسطات درجات طلاب مجموعات البحث في النطبيق القبلي لإختبار الوعي المعلوماتي ، ويوضح الجدول التالي نتائج التطبيق القبلي للإختبار : 
جدول (V) دلالة الفروق بين متوسطي القياس القبلي

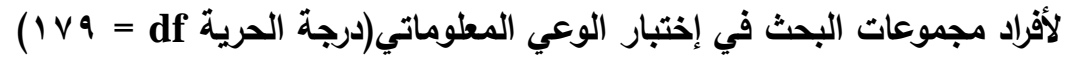

\begin{tabular}{|c|c|c|c|c|c|c|c|c|c|c|}
\hline \multicolumn{6}{|c|}{ Sig (p value) } & \multirow[b]{2}{*}{$\begin{array}{l}\frac{7}{3} \\
\frac{3}{9} \\
\frac{3}{3} \\
3\end{array}$} & \multirow[b]{2}{*}{$\begin{array}{l}\overline{3} \\
3 \\
3\end{array}$} & \multirow[b]{2}{*}{ 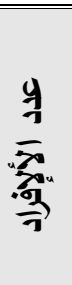 } & \multirow[b]{2}{*}{$\begin{array}{l}\frac{9}{3} . \\
\frac{9}{9} \\
\overline{7}\end{array}$} & \multirow[b]{2}{*}{$\frac{\overline{3}}{\overline{10}}$} \\
\hline 7 & 0 & $\varepsilon$ & $r$ & $r$ & 1 & & & & & \\
\hline $\begin{array}{c}. . V T \\
r\end{array}$ & $\begin{array}{c}.00 \\
\varepsilon\end{array}$ & $\begin{array}{c}. . \wedge V \\
q\end{array}$ & $\begin{array}{c}.0 \varepsilon \\
\varepsilon\end{array}$ & $\begin{array}{c}. \cdot v 4 \\
r\end{array}$ & * & $\begin{array}{c}1.11 \\
r\end{array}$ & 7.2 & rq & 1 & \\
\hline $\begin{array}{c}. .90 \\
r\end{array}$ & $\begin{array}{c}. \cdot r^{4} \\
r\end{array}$ & $\begin{array}{c}. .7 \varepsilon \\
9\end{array}$ & $\begin{array}{c}. . v 4 \\
r\end{array}$ & * & $\begin{array}{c}\cdot . v 4 \\
r\end{array}$ & $\begin{array}{c}1 . r 0 \\
1\end{array}$ & 7.4 & rq & $r$ & \\
\hline $\begin{array}{c}{ }^{*} \cdot{ }^{\prime} \\
r\end{array}$ & $\begin{array}{c}. .90 \\
r\end{array}$ & $\begin{array}{c}. . \leq \leqslant \\
q\end{array}$ & * & $\begin{array}{c}. \cdot v 4 \\
r\end{array}$ & $\begin{array}{c}. .0 \xi \\
\varepsilon\end{array}$ & $\begin{array}{c}1 . \pi \\
0\end{array}$ & 7.6 & Tr & $r$ & $q$ \\
\hline $\begin{array}{c}.7 \varepsilon \\
9\end{array}$ & $\begin{array}{c}. . \leq \varepsilon \\
q\end{array}$ & * & $\begin{array}{c}. . \leq \varepsilon \\
q\end{array}$ & $\begin{array}{c}. .7 \varepsilon \\
q\end{array}$ & $\begin{array}{c}\cdot . \wedge V \\
q\end{array}$ & $\begin{array}{c}1 . \varepsilon 1 \\
\varepsilon\end{array}$ & 7.1 & זr & $\varepsilon$ & 可 \\
\hline $\begin{array}{c}{ }^{*} \cdot{ }^{\prime} \\
r\end{array}$ & * & $\begin{array}{c}. . . \leq \varepsilon \\
q\end{array}$ & $\begin{array}{c}.90 \\
r\end{array}$ & $\begin{array}{c}\cdot . v 4 \\
r\end{array}$ & $\begin{array}{c}. .0\{ \\
\varepsilon\end{array}$ & $\begin{array}{c}1 . \pi \\
0\end{array}$ & 7.6 & ru & 0 & \\
\hline * & $\begin{array}{c}. . v 4 \\
r\end{array}$ & $\begin{array}{c}.7 \varepsilon \\
q\end{array}$ & $\begin{array}{c}. . v T \\
r\end{array}$ & $\begin{array}{c}. .90 \\
r\end{array}$ & $\begin{array}{c}. . V 4 \\
r\end{array}$ & $\begin{array}{c}1 . r 0 \\
1\end{array}$ & 7.4 & rı & 7 & \\
\hline
\end{tabular}

يتضح من الجدول السابق أن قيمة value بين المجموعات نتراوح بين 9؟؟ . .

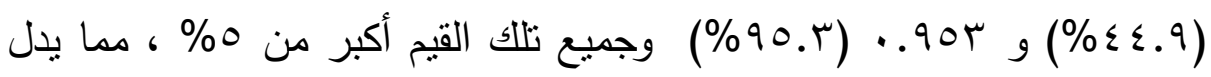
على أن الاختلافات بين المجموعات غير معنوي مما يدل على عدم وجود فروق

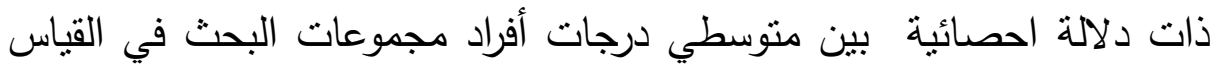
القبلي لإختبار الوعي المعلوماتي ، وبالتالي يؤكد وجود التكافؤ بين أفراد المجموعات في كل جوانب التطبيق العملي. 1 - تنفيذ تجربة البحث الأساسية : 
تم تعريض مجموعا البحث لمادة المعالجة التجريبية ، حيث قاموا بالتعامل مع البيئة الإلكترونية التي تحتوي على المحتوى العلمي في صورة إنفوجرافيك والخاص باكساب المفاهيم الخاصة بالوعي المعلوماتي ، بدأت تجربة البحث

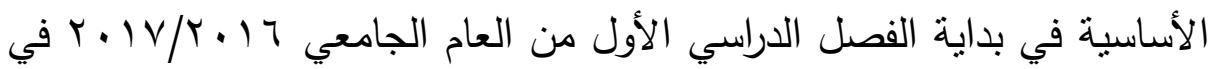

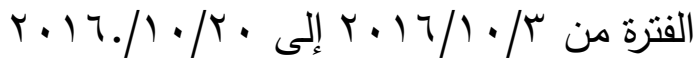

$$
\begin{aligned}
& \text { 9- تطبيق بعدي لأدوات البحث : }
\end{aligned}
$$

هدف التطبيق البعدي لإختبار الوعي المعلوماتي إلى التأكد من صحة فروض لإن البحث ولإجابة على الاسئلة البحثية وهذا موضح بالتفصيل في جزء النتائج في التي

$$
\text { البحثث الحالي. }
$$

1 - بالنسبة للسؤال الفرعي الأول والمرتبط به مدى تحقق الفرض الأول : تم إختبار الفرض الأول وهو : " توجد فروق ذات دلالة احصائية عند مستوى اهوى (0. (•) بين منوسطات درجات كل مجموعات البحث ، بين التطبيق القبلي والتطبيق البعدي في إختبار الوعي المعلوماتي ، لصالح التطبيق البعدي" ، وذلك من خلال إختبار قيمة "ت" لعينتين غير مستقلتين T test Paired Sample لحساب الفرق بين منوسطات درجات طلاب مجموعات البحث بين التطبيق

\begin{tabular}{|c|c|c|c|c|c|}
\hline إلتأثير & $\begin{array}{c}\text { مستوى } \\
\text { Sig (P } \\
\text { value) }\end{array}$ & قالمحسوية ت & الاتحراف المعياري & المتوسط & التطبيق \\
\hline..$A V$ & $\ldots$ & rq.VII & $1 . \leqslant 79$ & שמזי V & القبلي \\
\hline
\end{tabular}
القبلي والتطبيق البعدي في إختبار الوعي المعلوماتي ، وكانت النتائج كما يلي:

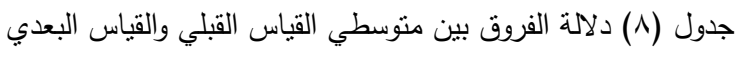




\begin{tabular}{|c|c|c|c|c|c|}
\hline إيتأثير & $\begin{array}{c}\text { مستوى الدلانة } \\
\text { Sig (P } \\
\text { value) } \\
\end{array}$ & قالمسة ت & الانحراف المعياري & المتوسط & التطبيق \\
\hline & & & מדזיT & 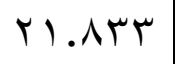 & البعدي \\
\hline
\end{tabular}

• أ- يتضح من الجدول السابق أن قيمة P.Value أقل من قيمة ه ه. . ، ويدل هذا على وجود فروق ذات دلالة إحصائية عند مستوى (0. . •) بين متوسطات درجات طلاب مجموعات البحث ككل لصالح التطبيق البعدي • ب - بلغت قيمة مربع إيتا ( NVV. • ) وهي قيمة تقترب من الواحد الصحيح

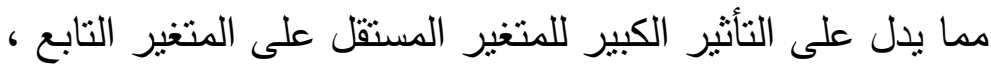
وبناء على أ ، ب يتم قبول الفرض الأول . يمكن تفسير تأثير الإنفوجرافيك في اكتسـاب مفاهيم الوعي المعلومـاتي بسبب مسـاهمته في اثاره اهتمام المتعلمين وحفزهم على عدم الثـعور بالملل وكذلك الثل

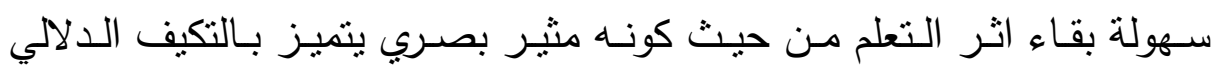
وتوظيفه للنص والصورة وأثنكال ورموز تساعد في فهم المحتوى ، وأيضـا سهولة

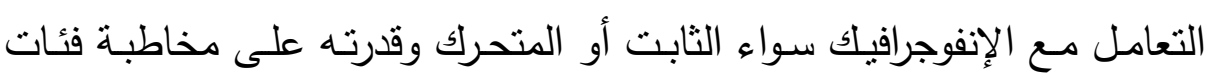
عمرية وثقافية مختلفة.

Ozdamlı, Kocakoyun, وجاءت هذه النتيجة للتوافق مع دراسات كل من(

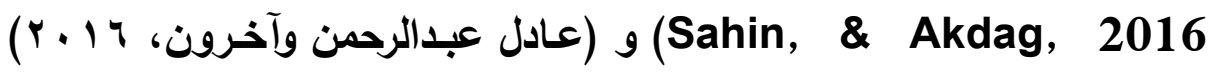

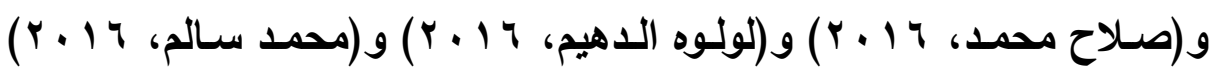

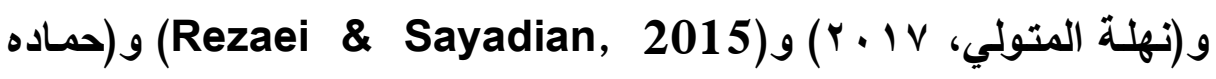

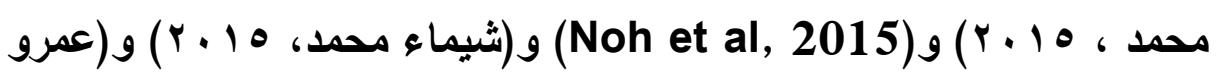

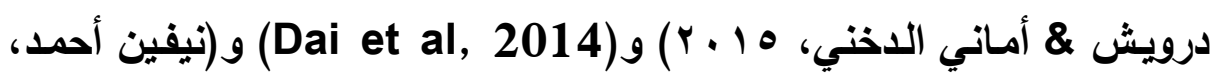


ع 1 • ب) و(Kibar \& Akkoyunlu , 2014) والتي أشنارت نتائجهم إلى فاعلية الإنفوجرافيك في تتمية التحصيل والاتجاهات ، وتتمية الملاحظة والنقد.

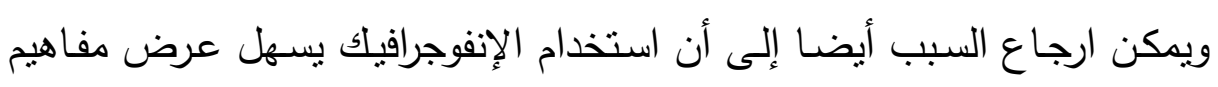
الوعي المعلوماتي وخطوات البحث عن المعلومات وكيفية تقييمها مما أدى إلى إنى

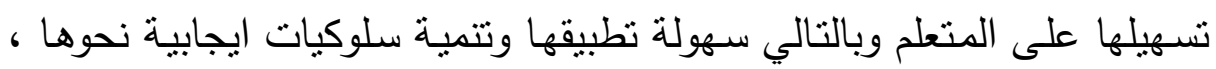
فمجرد تعرض المتعلم للإنفوجرافيك وما يعرضه من معلومات مختصرة وموجزة

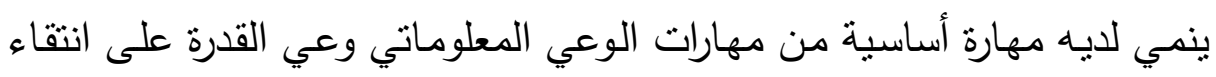

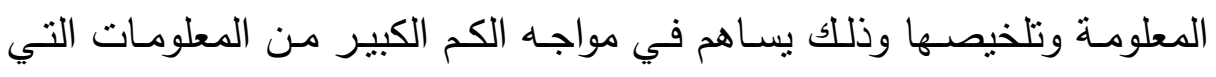
يتعرض لـه المتعلم من خـلال مصـادر التعلم المختلفة ، وبالتالي فإن استخدام مداخل تعلم غير تقليديـة سـاهم في اكتسـاب المتعلمين الجوانب المطلوبـة مـن الوعي المعلوماتي وهذه النتيجة نوافق مـع دراسـات كل مـن (سـاميه محمـد،

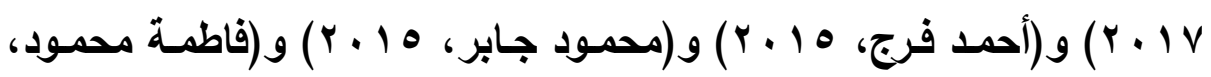

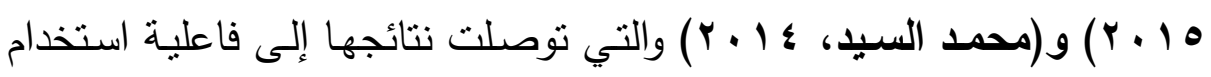
بيئات ومداخل تعلم غير تقليدية في تتمية مفاهيم ومهارات الوعي المعلوماتي

$$
\text { والاتجاهات نحوه. }
$$

2- بالنسبة للسؤال الفرعي الثاني والمرتبط به مدى تحقق الفرض الثاني: تم إختبار الفرض الثاني وهو: "توجد فروق ذات دلالة احصائية عند مستوى (0. . ) بين متوسطات درجات مجموعات البحث التي تدرس باستخدام الإنفوجرافيك الثابت وبين مجموعات

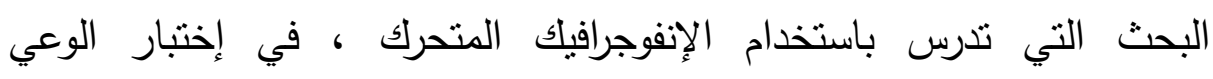
T test المعلوماتي " ، وذلك من خلا إختبار قيمة "ت" لعينتين مستقلتين Independent Sample مجموعات البحث (1-r-0) التي تدرس باستخدام الإنفوجرافيك الثابت وبين طلاب مجموعات البحث (ץ-乏 - 7) التي تدرس باستخدام الإنفوجرافيك المتحركة 
، وذلك في التطبيق البعدي لإختبار الوعي المعلوماتي ، وكانت النتائج كما يلي:

جدول (9) دلالة الفروق بين متوسطي مجموعتي البحث في القياس البعدي

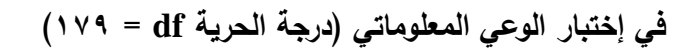

\begin{tabular}{|c|c|c|c|c|}
\hline $\begin{array}{l}\text { مستوى الالالة } \\
\text { Sig (P } \\
\text { value) }\end{array}$ & قالمسة ت & الانحراف & المتوبط & المجموعات \\
\hline \multirow{2}{*}{$\cdots$} & \multirow{2}{*}{ r.VVO } & r.ıN & r. . . & $\begin{array}{c}\text { الإنفوجرافيك الثابت } \\
(0-r-1)\end{array}$ \\
\hline & & I.ATV & YY.YTV & 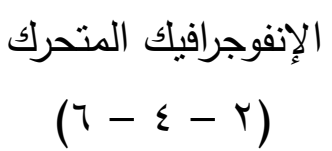 \\
\hline
\end{tabular}

يتضح من الجدول السابق أن قيمة P.Value أقل من قيمة ه ه. . هذا على وجود فروق ذات دلالة إحصائية عند مستوى (0. . •) بين متوسطات درجات طلاب مجموعات البحث لصالح مجموعات البحث التي تدرس باستخدام الإنفوجرافيك المتحرك ، وبالتالي يقبل الفرض الثاني. يرجع الباحث تفوق استخدام الإنفوجرافيك المتحرك مقارنـة بالإنفوجرافيك الثابت

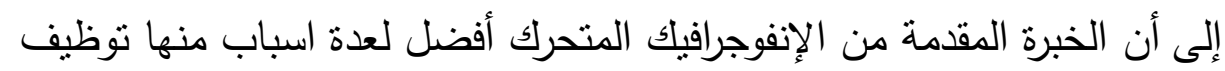


حاسـة الســع بالإضـافة إلى حاسـة البصـر في الإنفوجرافيك المتحرك مقارنــة بالإنفوجرافيك الثابت الذي يستخدم حاسة البصر فقط ، وكذلك قيام الإنفوجرافيك المتحرك بإعمال الذهن من خلال الحركات بحيث يربط بين المعلومات بسهولة يصعب نسيانها ، كما ان الإنفوجرافيك المتحرك يقوم بدمج العديد من الوسائط المتعددة على عكس الإنفوجرافيك الثابت الذي يعتمد على الصور فقط

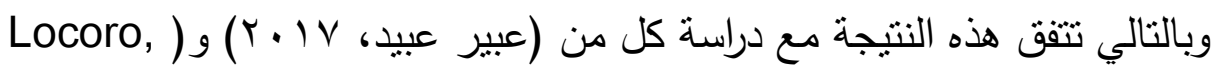
(Cabitza, Actis-Grosso, \& Batini, 2017 وجـود فـروق دالـة احصــائيا لصـالح اسـتخدام الإنفوجرافيـك المتــــك مقارنــة بالإنفوجرافيك الثابت. وتختلف تتفق هذه النتيجة مع دراسة (عمرو درويش \& أماني الدخني، 0 ( ب) والتي تتص على أنه استخدام الإنفوجرافيك الثابت أفضل لأن تصميمه يعتمد في الأساس على التجاور الزماني والمكاني بين النصوص والصور في آن واحد مما لإلى لايشكل عبئًا على الذاكرة العاملة ، وتختلف هذه الدراسـة أيضـا مع دراسـة (أمل حسن ، T ( • ب) والتي اظهرت نتائجها عدم وجود فروق دالـة احصـائيا بـين استخدام الإنفوجرافيك الثابت والإنفوجرافيك المتحرك r- بالنسبة للسؤال الفرعي الثالث والمرتبط به مدى تحقق الفرض الثالث: تم إختبار الفرض الثالث وهو : توجد فروق ذات دلالة احصائية عند مستوى (0...) بين متوسطات درجات مجموعات البحث في إختبار الوعي المعلوماتي نرجع إلى اختلاف السعة العقلية Oينهم ، وذلك من خلا إختبار تحليل التباين في اتجاه واحد ANOVA لحساب الفرق بين متوسطات درجات طلاب مجموعات البحث السعة

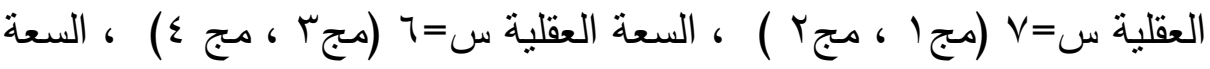
العقلية س = • (مجه ، مج)) وذللك في التطبيق البعدي لإختبار الوعي المعلوماتي ، وكانت النتائج كما يلي: 
جدول ( • 1) دلالة الفروق بين متوسطي مجموعات البحث في القياس البعدي

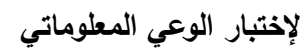

\begin{tabular}{|c|c|c|c|c|c|}
\hline $\begin{array}{l}\text { Sig (P } \\
\text { value) }\end{array}$ & قيمة (ف) & متوبط المربعات & درجات الحرية & المربعوع & مصدر التباين \\
\hline$\cdots \cdots$ & $18 \ldots \vee 9$ & $00.11 \mathrm{~V}$ & r & سזr.. 11 & المجموعات \\
\hline$*$ & $*$ & T.YYV & IVV & 114.90. & المجموعات \\
\hline$*$ & $*$ & $*$ & $1 \vee 9$ & rqะ.।1 & الاجمالي \\
\hline
\end{tabular}

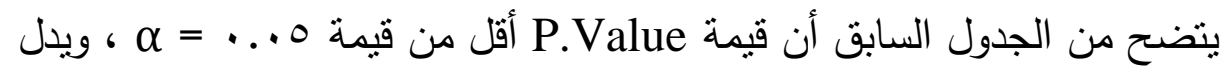
هذا على أن هنالك اختلاف بين المجموعات الثلاثة في التطبيق البعدي للإختبار وبالتالي هنالك مجموعتين على الأقل لها متوسطات غير منساوية ، ولتحديد مصدر الاختلاف ولتحديد صالح الفروق بين كل مجموعة على حدى تم استخدام إختبار LSD الذي جاءت نتائجه كما يلي:

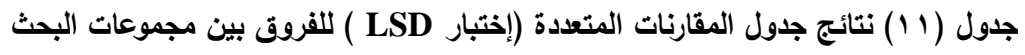
في التطبيق البعدي لإختبار السعة العقلية

\begin{tabular}{|c|c|c|c|c|c|c|}
\hline \multicolumn{2}{|c|}{ سعة عقلية منخفضة (r) مقة } & \multicolumn{2}{|c|}{ سعة عقلية متوسطة (Y) مقة } & \multicolumn{2}{|c|}{ سعة عقلية مرتفعة (1) } & \multirow{2}{*}{ بيان } \\
\hline $\begin{array}{l}\text { Sig }(P \\
\text { value })\end{array}$ & متوسط & $\begin{array}{l}\text { Sig }(\mathbf{P} \\
\text { value })\end{array}$ & متوسط & $\begin{array}{l}\text { Sig }(P \\
\text { value })\end{array}$ & متوسط & \\
\hline * & $*$ & * & * & & & W= \\
\hline * & $*$ & & & $\cdots \cdots$ & r.Ao. & س= \\
\hline & & .94. & $.0 \ldots$ & $\cdots$ & 2.900 & W= \\
\hline
\end{tabular}
يتضح من الجدول السابق ما يلي: 


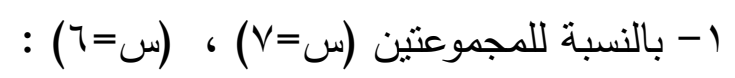

يتضح من الجدول السابق أن قيمة P.Value تساوي ( ( ....) وهي أقل من مستوى 0 . . . وبالتالي توجد فروق بين المجموعتين لصالح المجموعة (س = V)

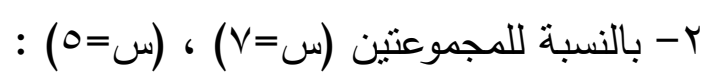
يتضح من الجدول السابق أن قيمة P.Value تساوي ( ( ....) وهي أقل من

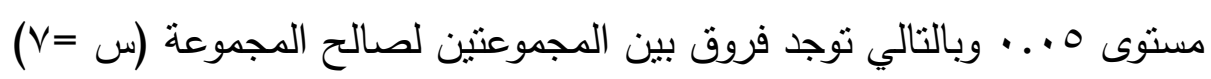

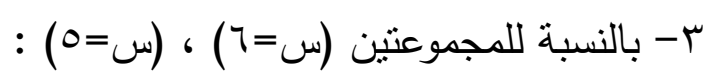
يتضح من الجدول السابق أن قيمة P.Value تساوي ( • بو. •) وهي أكبر من مستوى 0 .. . وبالتالي لا توجد فروق بين المجموعتين من l ، Y ، r يتضح وجود فروق ذات دلالة احصائية بين المجموعات حيث أن المجموعة ذات السعة العقلية (س=ول) حازت أفضل النتائج يليها بشكل متساوي تقريبا ذوي السعة العقلية (س=ף) وذوي السعة العقلية (س=ه) ، وبالتالي يقبل الفرض الثالث يمكن تفسير اختلاف نتائج اكتساب الوعي المعلوماتي بسبب اختلاف السعات

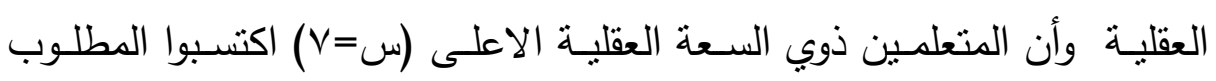

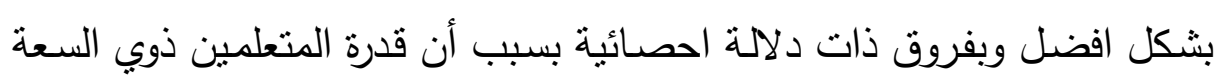
العقلية الأفل (س=7 ) و (س=0) على فهم التركيب البصري للأشكال الورادة

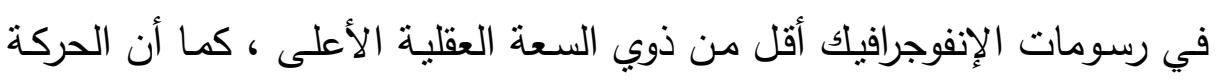

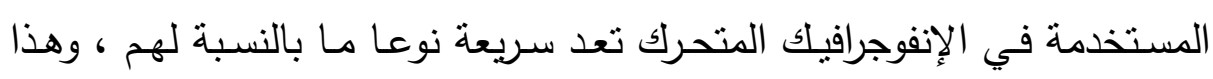

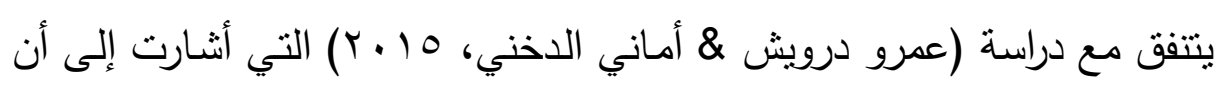
قاعدة التجاور المكاني تفسر الفروق الفردية في انقرائية الإنفوجرافيك والتي ترجع إلى قدرة الذاكرة العاملة على الاحتفاظ بالصور والكلمات المعروضة على الثناشة الثنة والتي تعد منوسطة بالنسبة لذوي السعة العقلية (س=7 ، س=ه) الذي يبذلون 
جه أكبر من ذوي السعة العقلية (س=V) وذلك في البحث عن مصادر معرفية على الثاشة خصوصا في الإنفوجرافيك المتحرك ويمكن ارجاع السبب أيضـا إلى أن الفروق الفردية بين المتعلمين في الاسـاليب

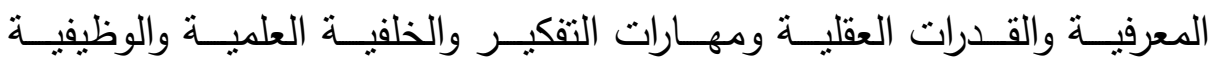
والتخصصـات التي يدرسونها تؤدي بالتالي إلى وجود فروق فردية في اكتساب

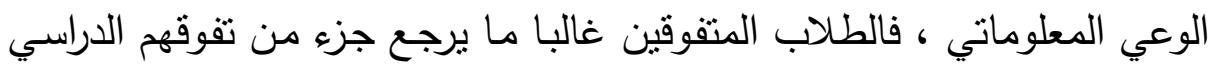

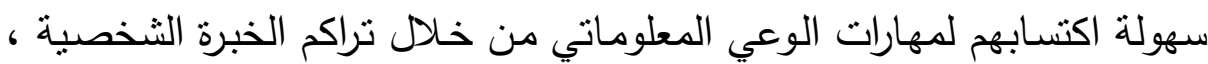

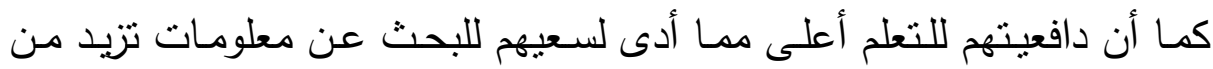
معدلات تفوقهم الدراسي ومنها الوعي المعلوماتي • وهذه النتيجـة نوافـق مـع دراسـات كل مسن (إيمـان جميـل \& \& إبـراهيم حريـي،

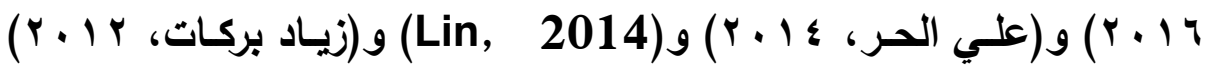

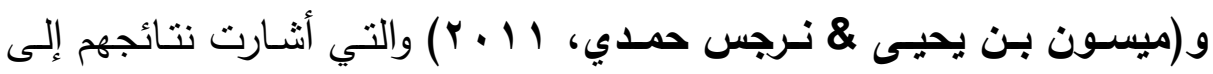
وجود فروق في مدى اكتسـاب مفاهيم ومهارات الوعي المعلومساتي ترجع إلى

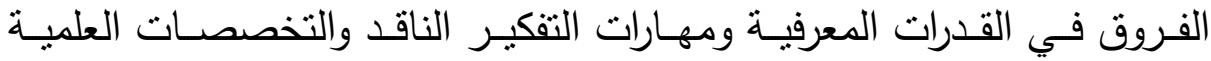

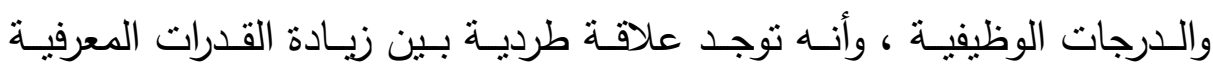
ومهارات التفكير وبين اكتساب مفاهيم ومهارات الوعي المعلوماتي كذلك يمكن تقسير النتيجـة الحاليـة بسـبب تميـز الطـلاب ذوي السـعة العقليـة المرتفعة عن أقرانهم ذوي السعة العقلية الاقل في قدرتهم على دمج أكبر عدد من المعلومات المتاحة واللازمة لحل المشكلة في مخططات معرفية أقل بما لايسبب تحميلا زائدا على سـتهم العقلية ، وبزيادة السعة العقلية تزداد مسـاحة التفكير وبالتالي زيادة قدرته على التعامل مـع المعلومـات التي تتطلبها حل المشكلة ، كذلك وجود علاقة ببين السعة العقليـة والتحصيل حيث أن السعة العقليـة تقل كفاءتها بسبب الحمل الزائد في المعلومات 


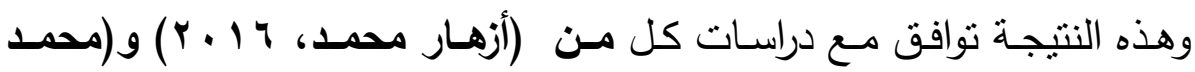

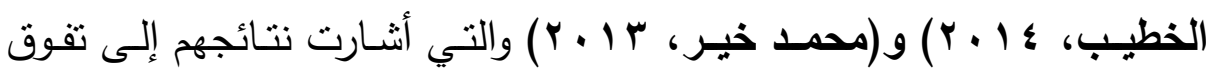
الطلاب ذوي السعة العقلية في اكتساب المفاهيم والمهارات المطلوبـة في مختلف المقررات الدراسية والمواقف التعليمية ، وأن تتظيم المحتوى الدراسي في ضوء متغير السعة العقلية قد يساعد المتعلمين خصوصا ذوي السعة العقلية المنخفضـة على تتظيم الافكار وتتابعها ممـا يقلل الجهد المبذول في تـكر المعلومـات المتفرقة المتباعدة ومن زيادة ادراك العلاقات بين المحتوى وزيادة التحصيل ع - بالنسبة للسؤال الفرعي الرابع والمرتبط به مدى تحقق الفرض الرابع : تم إختبار الفرض الرابع وهو : توجد فروق ذات دلالة احصائية عند مستوى (0... بين منوسطات درجات مجموعات البحث في إختبار الوعي المعلوماتي يرجع لتأثنر التقاعل المتبادل بين اختلاف نمطي الإنفوجرافيك المقدم (الثابت - المتحرك) وبين اختلاف مستوبات السعة العقلية لدى الطلاب ، وذلك من خلال إختبار تحليل التباين في اتجاهين مع اعتبار التأثير المتبادل بين المتغيرين المستقلين ( Two way (ANOVA النطبيق البعدي لإختبار الوعي المعلوماتي وفق مستويات السعة العقلية، وكانت النتائج كما يلي: 
جدول (r I ) دلالة الفروق بين متوسطي مجموعات البحث في القياس البعدي لإختبار الوعي المطوماتي مجموعات

\begin{tabular}{|c|c|c|c|c|c|}
\hline $\begin{array}{l}\text { Sig (P } \\
\text { value) }\end{array}$ & قيمة (ف) & متوبط المربعاث & الحرباتة & مجموع المربعاث & مصدر التباين \\
\hline$\ldots$ & $r \leqslant .9 r \leqslant$ & $0 \Lambda . \cdot 1 \mathrm{~V}$ & 1 & $0 \Lambda . .1 \mathrm{~V}$ & نمط الإنفوجرافيك \\
\hline$\ldots$ & r.7VA & $00.11 \mathrm{~V}$ & $r$ & سזr.. & السعة العقلية \\
\hline. .901 &. .0. &. $.11 \mathrm{~V}$ & r & חזr.. & نمط الأنثير المتبادل بين \\
\hline * & * & r.r & $1 \vee \varepsilon$ & Iro.V.. & الخطأ \\
\hline * & * & * & $1 \vee 9$ & $r q \leq .1 \wedge r$ & الإجمالي \\
\hline
\end{tabular}

يتضح من الجدول السابق ما يلي : ا - تأثير منغير (نمط الإنفوجرافيك): يتضح من الجدول السابق أن قيمة P.Value تساوي ( ( . . . . ) وهي أقل من مستوى مستوى 0 . . • ، وبالتالي وجود فروق ذات دلالة إحصائية عند مستوى ه . . بين متوسطات درجات طلاب كافة المجموعات برجع لتأثير نمط الإنفوجرافيك r- تأثير منغير (مستوى السعة العقلية): يتضح من الجدول السابق أن قيمة P.Value تساوي ( . . . . . ) وهي أقل من مستوى مستوى 0 . . . ، وبالتالي وجود فروق ذات دلالة إحصائية عند مستوى ه . . بين متوسطات درجات طلاب كافة المجموعات يرجع لتأثير اختلاف مستوى السعة العقلية

ب- التفاعل المنبادل بين (نمط الإنفوجرافيك) وبين (مستوى السعة العقلية) : يتضح من الجدول السابق أن قيمة P.Value تساوي (101. • ) وهي أكبر من 
مستوى مستوى 0.. مستوى 0.. التفاعل بين (نمط الإنفوجرافيك ، مستوى السعة العقلية) ، وبالتالي يتم رفض

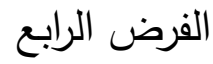
كذلك يمكن تفسير نتيجة عدم وجود فروق ذات دلالة احصائية بين الطلاب ذوي السعة العقلية (س=7) و (س=0) في اكتساب مفاهيم الوعي المعلوماتي إلى أن الإنفوجرافيك قـام بعدل تتظيم للمعلومـات بسـرعة وبشكل واضـح بشكل جميل وجذاب مما أدى إلى تقليل الفروق الفردية بين الطلاب الذين ينتمون إلى هذين المستوبين من السعة العقلية وبالتالي عدم وجود فروق ذات دلالة إحصائية بين مجموعات ثلك المستويات ، كما يمكن تفسير عدم وجود تأثنير متبادل بشكل كامل لجميع مستويات السعة العقلية لجميع طلاب مجموعات البحث إلى وجود متغيرات أخرى نؤثز في استيعاب المتعلم للإنفوجرافيك مثل أنماط التعلم فكما أثنارت دراسة (Lovelace , 2005) فإن نمط التعلم لايتعلق بالذكاء أو بالسعة العقلية وإنماط يتعلق بالاسلوب التعليمي المفضل لاى المتعلم والذي يعطي نتائج أفضل فوفقا لنموذج VAK لانماط التعلم فإن المتعلم ذو نمط التعلم البصري يركز على الاثياء المرئية مثل الإنفوجرافيك على عكس ذوي نمط التعلم السمعي أو الحسي ، وبالتالي فان البحث الحالي أثنار إلى أن متغير السعة العقلية غير ماءلى مرتبط منفرادا بمدى استيعاب الطلاب للمعلومات من خلال الإنفوجرافيك سواء الثابت أو المتحرك. القيمة التريوية للبحث : تتمثل القيمة التربوية للبحث فيما يلي 1- الطـلاب : تتضـح في تدريبهم على التعامـل مـع الإنفوجرافيك بأنواعـهـ المختلفة كمثير بصري غير تقليدي يقدم المحتوى التعليمي في صسورة 
جديدة وشيقة ؛ خاصة في عصر المعلوماتية وما يفرضـه من ضروروة التعامل مـع متغيرات العصر من خـلال الحصـول على المعلومـات من لن مصـادر متتوعـة ومختصـرة ، كم أن الوعي المعلومـاتي أصبح ضـرورة تربوية لاغنى عنها من أجل تأسيس فكر معلومـاتي بين أفراد المجتمع يجعلهم قادرين على انتقاء احتياجاتهم المعلوماتية بشكل صحيح وفعال. r- المعلمسين وأعضـاء هيئة التـدريس : التأكيد على دورهم في توظيف تقنيـات حديثة وبسـيطة في التعليم تسـاعد على جذب انتبـاه المـتعلم وتوصيل كمية من المعلومات بشكل سريع ومبسط ، وكذللك التأكيد على التفكير في استراتيجيات تعليمية تراعي الاختلاف في مستويات السعة العقلية بين المتعلمين.

r- العملية التعليمية: توفير طريقة تعليمية تطور وتتمي الوعي المعلوماتي بمـا يسـهم في إنتاج فرد واعي معلومـاتي قـادر على إدراك المعلومـات

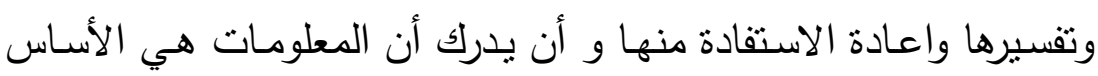

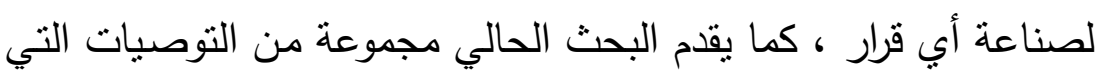
تسهم في زيادة الوعي الهني وأيضا مراعاة السعة العقلية للمتعلمين. ع - البحث العلمي: لم يعد استخدام الإنفوجرافيك بشكل عام موضوعا بحثيا وإنما المفاضلة بين أنواعه المختلفة في ضوء متغيرات تصنيفية ، كذلك

$$
\text { توصيات البحث: البحث الحالي بعض البحوث المقترحة. }
$$

1- التوسع في استخدام الإنفوجرافيك عن طريق تحويل بعض موضوعات المقررات الدراسية لمختلف المراحل لإنفوجرافيك لما لها من نأثير فعال. 
r- الاهتمام بمراعاة الاختلاف بين مستويات السعة العقلية للمتعلمين بكافة

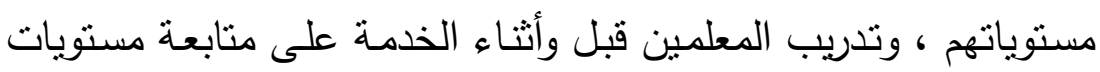
الطلاب في ضوء تلك المستويات r- ضرورة تتمية الوعي المعلوماتي لدى جميع المتعلمين نظرا لأنها مهارة عامة تفيد الجميع في حياتهم العملية والأكاديمية.

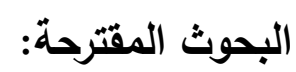

1- دراسـة اثر متغيرات مستقلة أخرى تتمي الوعي المعلوماتي مثل الخرائط

$$
\text { الذهنية والرسومات التعليمية المتحركة }
$$

r- دراسة اثز الإنفوجرافيك التفاعلي في تتمية الوعي المعلوماتي

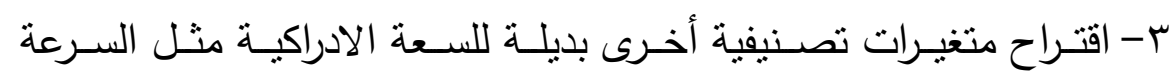

الادراكية والتفكير الناقد والقدرة على حل المشكلات ع- تجربة البحث على فئات أخرى غير التي استخدامها في البحث الحالي.

\section{المراجع والمصادر}

أحمد فرج أحمد (2015) دور البرامج الأكاديمية تجاه تطوير مهارات الوعي

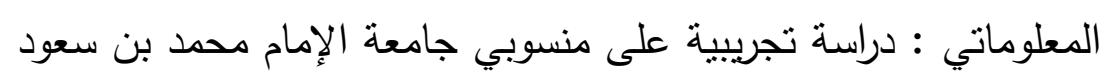

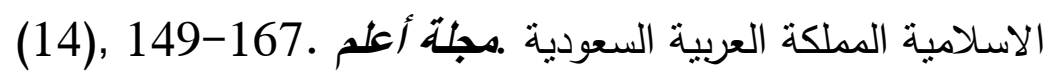
أروى محمد حلواني (^ . . ؟). برامج الوعي المعلوماتي في مكتبة الملك عبد اله بن عبد العزيز الجامعية ومدى الإفادة منها. ورقة بحث مقدمة إلى برانى

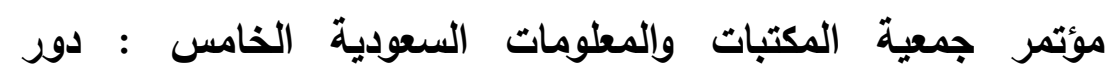
مؤسسات المعلومات في المملكة في عصر مجتمع المعرفة : تعديات الواقع وتطلعات المستقبل، جده.

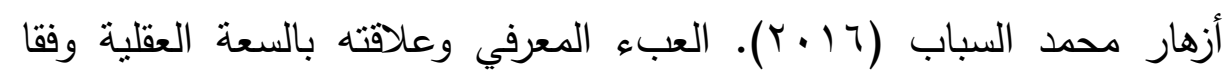

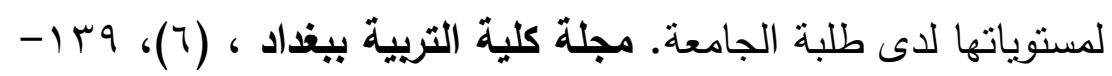


أماني زكريا الرمادي (10 ( ب). إعداد إختبار لتحديد مستوى الوعي المعلوماتي للى طلاب الجامعات المصرية. مجلة بحوث في علم المكتبات

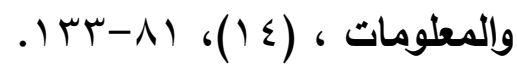
أماني محمد ثابت زين الدين (ع ا • ب). معايير الوعي المعلوماتي في مرحلة التعليم الجامعي : دراسة تحليلية للمعايير العالمية مع دراسة لنماذج من برامج الوعي المعلوماتي في مصر لاقتراح معيار اقليمي رسالة ماجستير ، جامعة الاسكندرية.

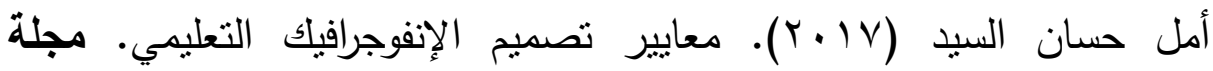

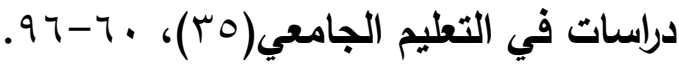
إيمان جميل عبدالفتاح \& إبراهيم حربي تادرس (T ( ب). مستوى الوعي المعلوماتي في المجتمع الاكاديمي دراسة ميدانية على أعضاء هيئة

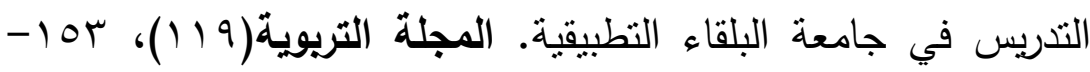
.194

إيمن مصطفى الفخراني (10 ( ب). الوعى المعلوماتى : دراسة تطبيقية على

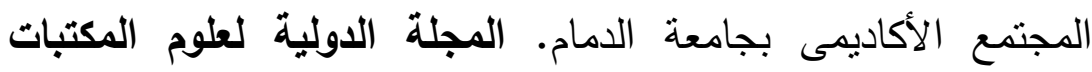

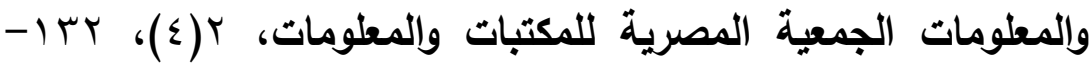
$.1 V 7$ ثروت فتحي كامل (T (Y). دور الصحافة المدرسية الإكترونية في تتمية الوعي المعلوماتي لدى طلاب المرحلتين الإعدادية والثانوية. مجلة

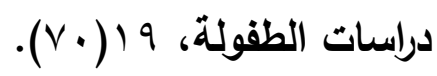
حسن خليل ابراهيم (ب ( + Y). الذاكرة العاملة وماوراء الذاكرة وعلاقتهما بالضغوط النفسية لدى طلبة الجامعة. رسالة دكتوراه ، جامعة بغداد. 
حماده محمد مسعود (10 + (Y). فاعلية استخدام تقنية الإنفوجرافيك (قوائم علاقات) في تتمية مهارات تصميم البصريات لدى طلاب التربية الفنية المستقلين والمعتمدين بكلية التربية. مجلة دراسات عريية في التربية

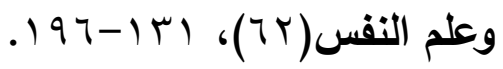

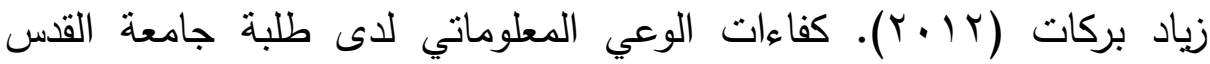
المفتوحة في منطقة طولكرم التعليمية وفق المعايير العالمية. مجلة

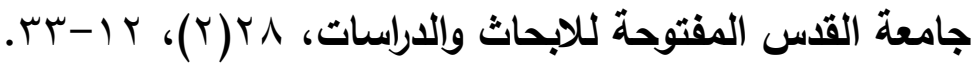
سماح صلاح هاشم (Y ( (Y). تعلم المهارات المعلوماتية في المرحلتين الاعدادية والثانوية في جمهورية مصر العربية. رسالة ماجستير ، كلية الاداب جامعة الاسكندرية. سماح صلاح هاشم (Y (Y). تعليم المهارات المعلوماتية في المرحلتين الإعدادية والثانوية في جمهورية مصر العربية: دراسة تقويمية وتخطيطية. رسالة ماجستير، كلية الاداب ، جامعة الاسكندرية. شاكر عبدالعظيم \& شحاته محروس (ع ( • ץ). مدى وعي طلاب كلية التربية بمهارات الكتابة الإلكترونية (E-Writing) وبمعايير الوعي المعلوماتي للتعليم العالي في تواصلهم الالكتروني ورقة بحث مقدمة في مؤتمر السنوي لكلية التربية بجامعة حلوان والذي عقد في ع الب بـ ، كلية التربية جامعة حلوان. شيماء محمد أبوعصبه (10 • (Y). اثر استخدام استراتيجية الإنفوجرافيك على تحصيل طالبات الصف الخامس الأساسي واتجاهاتهن نحو العلوم ودافعيتهم نحو تعلمها. رسالة ماجستير، كلية الدراسات العليا ، جامعة

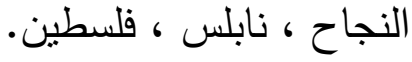


صلاح محمد جمعه (T ( + r). استخدام الإنفوجرافيك في تدريس الجغرافيا لتنمية التحصيل و مهارات التفكير البصري لدى طلاب المرحلة الثانوية. مجلة

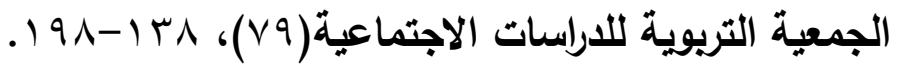
صلاح محمد جمعه (T ( + ( ). استخدام الإنفوجرافيك في تدريس الجغرافيا لتتمية التحصيل و مهارات التفكير البصري لدى طلاب المرحلة الثانوية. مجلة

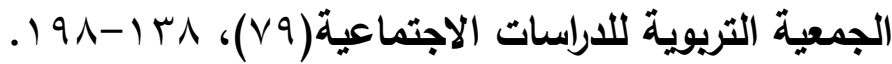
عادل عبدالرحمن \& عبير السيد \& إيناس عبدالرؤوف (2016) دراسة تحليلية للإنفوجرافيك ودوره في العملية التعليمية في سياق الصياغات التشكيلية (47), للنص وعلاقة الكتابة بالصورة .مجلة البحوث في التربية والقنونية

$$
10-17 \text {. }
$$

عبدالرؤوف محمد محمد اسماعيل (T ( + ب). استخدام الإنفوجرافيك " التفاعلى / الثابت " وأثزه فى تتمية التحصيل الدراسى لدى طلاب تكنولوجيا التعليم

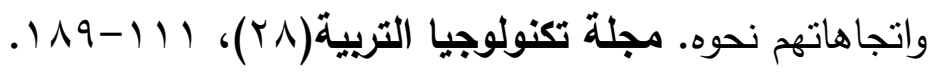
عبداللطيف عبدالقادر أبوبكر (r (r). أثز تدريس الأدب بالمرحلة الثانوية في ضوء مستويات السعة العقلية في تحصيل الطلاب واتجاهاتهم. مجلة

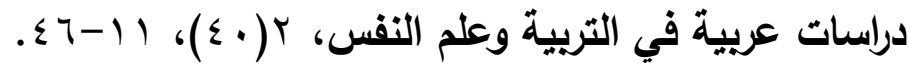
عبداله عصام سليمان (ع ا • Y). السعة العقلية وعلاقتها بمفهوم الذات واتخاذ القرار لدى طلبة المرحلة الاعدادية. رسالة دكتوراه ، كلية التربية جامعة تكريت.

علي الحر لازم (ع ( • ب). قياس الوعي المعلوماتي لطلبة الجامعة المستتصرية.

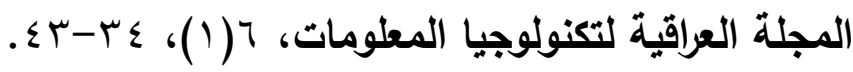
علي مردد موسى العمري (ع ( ب). أثز استخدام مصادر المعلومات الإلكترونية في تدريس مقرر المهارات الحياتية على تتمية التفكير الناقد والوعي 
المعلوماتي لدى طلاب المرحلة الثانوية رسالة دكتوراه ، كلية التربية ،

$$
\text { جامعة أم القرى. }
$$

عمرو محمد درويش \& أماني أحمد الدخني(10 • ب). أنماط تقديم الإنفوجرافيك الثابت والمتحرك عبر الويب واثرهما في في تتمية مهارات التفكير

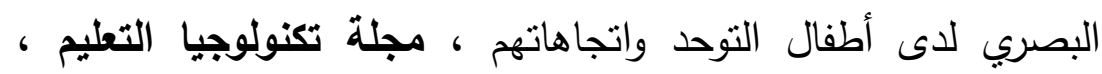

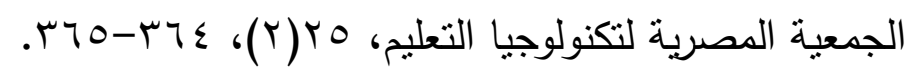
فاتن عطيه محمد \& صفاء عبدالعزيز محمد \& شاكر عبدالعظيم محمد(T 1 Y). تصميم برنامج قائم على النظرية البنائية لتتمية مهارات التواصل الثفوي والوعي المعلوماتي لدى متعلمي اللغة العربية الناطقين

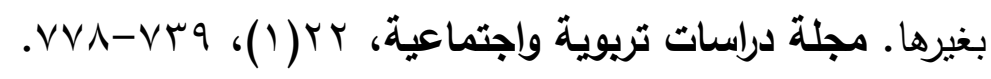
فاطمة محمود الزيات (2015) برنامج تدريبي قائم على مهارات التفكير الناقد التمييزية لتتمية الوعي المعلوماتي لدى طلاب الدراسات العليا .مجلة

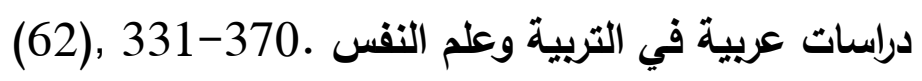
فاطمه محمود الزيات (10 ( ب). برنامج تدريبي قائم على مهارات التفكير الناقد

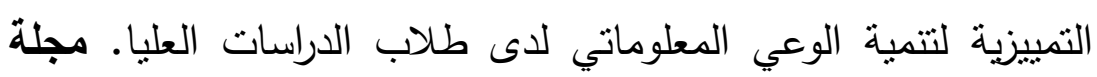

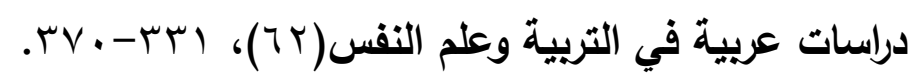
لولوة علي الدهيم (2016) أثز دمج الإنفوجرافيك فى الرياضيات على تحصيل (7), 19, طالبات الصف الثانى المتوسط .مجلة تريويات الرياضيات

$$
\text { 263-281. }
$$

محمد أحمد الخطيب (ع ا • r). أثر بنية المشكلة الرياضية (السياق - المحتوى - عدد خطوات الحل) في القدرة على حلها لاى طلاب الصف الثاني المتوسط من ذوبي السعات العقلية المختلفة في المدينة المنورة. مجلة

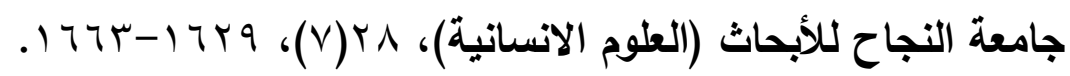
محمد اسيد سليمان (ع ( †). فاعلية التدريب على إستخدام نظام إدارة التعلم 
والمحتوى الإلكتروني في تتمية الوعي المعلوماتي ومهارات التعلم الإكتروني لاى أعضاء هيئة التدريس بجامعة طيبة. مجلة كلية التربية

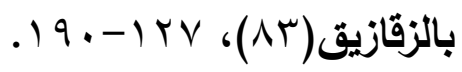

محمد خير محمود (Y (Y. T). اثز تدريس العلوم بطريقة الأنشطة العلمية في تحصيل الطلبة ذوي السعات العقلية المختلفة للمفاهيم العلمية وتتمية اتجاهاتهم العلمية. مجلة اتحاد الجامعات العربية للتربية وعلم النفس،

$$
.9 V-V) ،(r) 11
$$

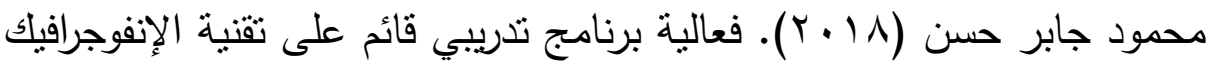
في تتمية مهارات إعداد ملف الإنجاز والإتجاه نحوه لدى الطلاب المعلمين بمدارس التربية الفكرية بالإحساء. المجلة العربية لاراسات ويحوث العلوم

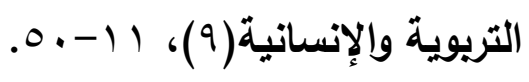

مروة السيد سعيد \& سليمان بن ابراهيم الرباعي (Y V (Y). الوعي المعلوماتي

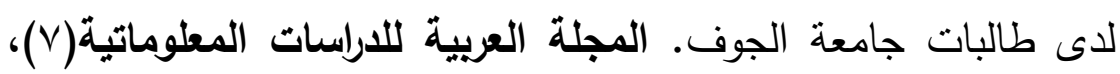

$$
.9 r-\varepsilon r
$$

ميسون حسين طاهر بن يحيى \& نرجس عبدالقادر حمدي (1) ( + (1). مدى وعي طلاب الدراسات العليا في الجامعة الأردنية لمفهوم التتور المعلوماتي

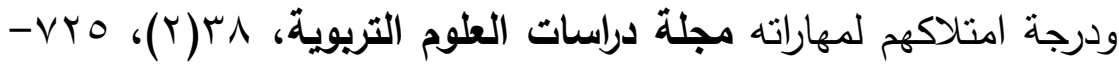
.Vo.

Dai, \& Siting. (2014). Why should PR professionals 
embrace infographics ? . University of Southern California.

Edwards, S. J. (2017). Cultural conceptions of mental capacity. sagepub, 13(2), 54-58. doi: $10.1177 / 1747016117718727$

Harvey, K. (2014). Infographic Encyclopedia of Social Media and Politics: SAGE Publication Inc. Thousands Oaks.USA.

Jabr, R. (2016). Infographics: Students Presenting Information in Bytes. TESOL Arabia, 24(1), 3335 .

Kibar, P. N., \& Akkoyunlu, B. (2014). A New Approach to Equip Students with Visual Literacy Skills: Use of Infographics in Education. Paper presented at the Lifelong Learning and Digital Citizenship in the 21st Century, ECIL 2014.

Lee, J. W., \& Cavanaugh, T. (2016). Building your brand: The integration of infographic resume as student self-analysis tools and self-branding resources. Journal of Hospitality, Leisure, Sport \& Tourism Education, 18 , 61-68. doi: 10.1016/j.jhlste.2016.03.001

Lin, S.-S. (2014). Science and non-Science undergraduate 
students critical thinking and argumentation Performance in reading a science news Report International Journal of Science and Mathematics Education, 12(5), 1023-1046.

Locoro, A., Cabitza, F., Actis-Grosso, R., \& Batini, C. (2017). Static and interactive infographics in daily tasks: A value-in-use and quality of interaction user study. Computers in Human Behavior, 71, 240-257. doi: 10.1016/j.chb.2017.01.032

Meacham, M. (2015). Use Infographics to Enhance Training. Talent Development, 69(8), 76-77. Noh, M. (2015). The Use of Infographic as a tool of felicitating learning Hasdinor Oskar.

Ozdamlı, F., Kocakoyun, S., Sahin, T., \& Akdag, S. (2016). Statistical Reasoning of Impact of Infographics on Education. Procedia Computer Science, 102, 370-377. doi: 10.1016/j.procs.2016.09.414

Rezaei, N., \& Sayadian, S. (2015). The Impact of Infographics on Iranian EFL Learners' Grammar Learning. Journal of Applied Linguistics and Language Research, 2(1), 78-8.

Siricharoen, W. V., \& Siricharoen, N. (2015). How Infographic should be evaluated? Paper presented at the The 7th International 
Conference on Information Technology.

TD. (2015). E-Learning Infographics. Talent Development, 69(3), 13.

Thompson, J. E. (2016). Four tips for school-specific infographics. Techniques: Connecting Education \& Careers, 91(7), 8-9. 